\title{
WestVirginiaUniversity
}

THE RESEARCH REPOSITORY @ WVU

Graduate Theses, Dissertations, and Problem Reports

2013

\section{Absorption of Marine vs Non-Marine sources of EPA and DHA}

John S. Ketz

West Virginia University

Follow this and additional works at: https://researchrepository.wvu.edu/etd

\section{Recommended Citation}

Ketz, John S., "Absorption of Marine vs Non-Marine sources of EPA and DHA" (2013). Graduate Theses, Dissertations, and Problem Reports. 3613.

https://researchrepository.wvu.edu/etd/3613

This Thesis is protected by copyright and/or related rights. It has been brought to you by the The Research Repository @ WVU with permission from the rights-holder(s). You are free to use this Thesis in any way that is permitted by the copyright and related rights legislation that applies to your use. For other uses you must obtain permission from the rights-holder(s) directly, unless additional rights are indicated by a Creative Commons license in the record and/ or on the work itself. This Thesis has been accepted for inclusion in WVU Graduate Theses, Dissertations, and Problem Reports collection by an authorized administrator of The Research Repository @ WVU. For more information, please contact researchrepository@mail.wvu.edu. 


\title{
Absorption of Marine vs Non-Marine sources of EPA and DHA
}

\author{
John S. Ketz \\ Thesis submitted to the \\ Davis College of Agriculture, Natural Resources, and Design \\ At West Virginia University \\ In partial fulfillment of the requirements \\ For the degree of \\ Master of Science \\ In \\ Animal Physiology
}

Kimberly M. Barnes, PhD., Chair

Kenneth P. Blemings, PhD.

P. Brett Kenney, PhD.

Department of Animal and Nutritional Sciences

West Virginia University

Morgantown, WV

2013

Keywords: omega-3, fatty acids, fish oil, algae oil, yeast oil, lipid, absorption

Copyright 2013 John S. Ketz 


\title{
Abstract \\ Absorption of Marine vs Non-Marine sources of EPA and DHA \\ John S. Ketz
}

\begin{abstract}
Docosahexaenoic acid (DHA) from algae oil has been incorporated into tissues at a lower level and has been less effective than fish oil (FO) at reducing body fat. Our objective was to determine fecal excretion of eicosapentaenoic acid (EPA) and DHA from different dietary sources. Male mice $(\mathrm{n}=100)$ were fed a $12 \%$ lipid diet containing soy oil (SO), FO, yeast oil (YO) algae oil (AO), or AO+YO. The AO diet was fed to contain amounts of DHA equal to the FO diet, and the YO diet was fed to contain amounts of EPA equal to the FO diet. To measure absorption, fecal samples were collected over night once per week for 4 weeks, and fatty acid composition was analyzed. Muscle and adipose tissue were collected and analyzed for fatty acid composition. There were no differences in feed intake, body weight, or body fat $(\mathrm{P}>0.05)$. FO-fed mice did have heavier livers $(\mathrm{P}<0.05)$. AO+YO-fed mice had greater fecal DHA content than AO- and FO-fed mice for the first 3 weeks $(\mathrm{P}<0.05)$, and AO-fed mice had greater $(\mathrm{P}<0.05)$ fecal DHA content than FO-fed mice in weeks 2-4. FO-fed mice had greater fecal EPA than YO- and AO+YOfed mice at week one $(\mathrm{P}<0.05)$. FO- and YO-fed mice had greater fecal EPA at week 1 than at weeks 2-4 $(\mathrm{P}<0.05)$. FO-fed mice had the greatest muscle tissue EPA content $(\mathrm{P}<0.05)$ at weeks 2 and 4 . FO-fed mice had the greatest adipose tissue EPA and DHA content at week $4(\mathrm{P}<0.05)$. At week 2, adipose tissue of FO-fed mice contained more EPA than adipose tissue of YO-fed mice $(\mathrm{P}<0.05)$, and more DHA than adipose tissue of AO-fed mice $(\mathrm{P}<0.05)$. Thin layer chromatography was performed and verified that the oil sources were primarily composed of triglycerides. Positional analysis of the oils was performed with a lipase and showed enrichment of DHA in FO at the sn-2 position. In conclusion DHA in FO is more available than in AO, because of the position of DHA on the triglyceride structure, and EPA and DHA from $\mathrm{FO}$ is more highly incorporated than from $\mathrm{YO}$ or $\mathrm{AO}$.
\end{abstract}




\section{Acknowledgements}

First I would like to thank my advisor Dr. Barnes for letting me work on this project and guiding me along the way. I also want to thank Dr. Kenney and Dr. Blemings for agreeing to be on my committee and for their advice and support throughout my time in school. I would like to thank Mary Rodavich who worked on this project with me, Dr. Siri Ippagunta who helped me in the lab whenever I needed it, and Susan Slider who helped me with all of the fatty acid work. Also I would like to acknowledge all my friends and family for their support throughout my work on this project. 


\section{Table of Contents}

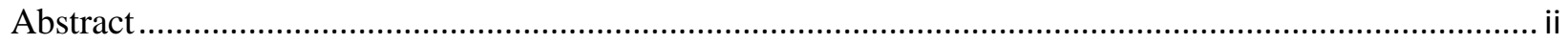

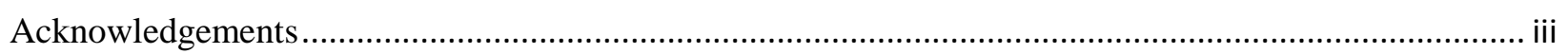

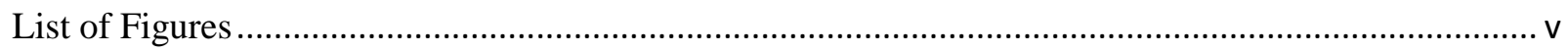

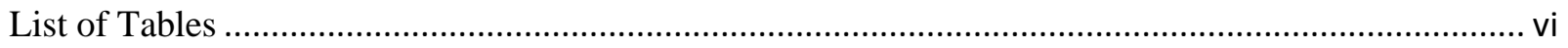

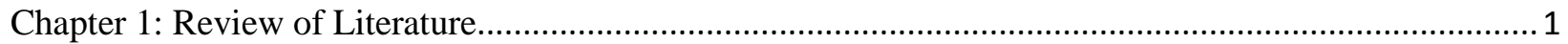

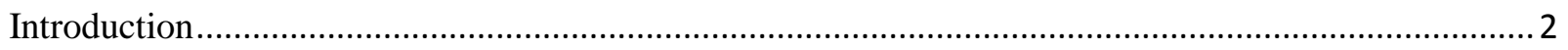

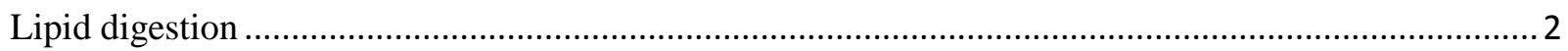

Fatty Acid and Monoglyceride Uptake into Enterocytes .................................................................... 4

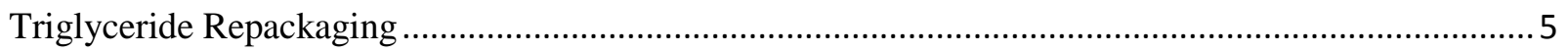

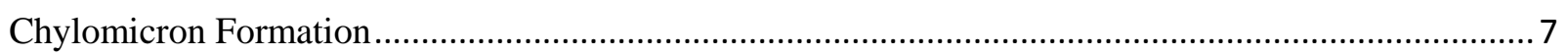

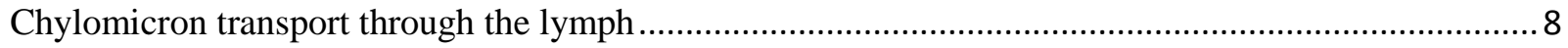

Lipoprotein Lipase; Structure, Action, and Regulation ................................................................. 9

Uptake of Fatty Acids and 2-Monoacylglycerols ........................................................................ 11

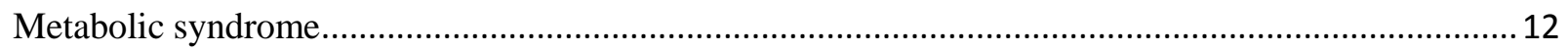

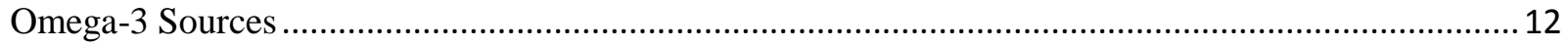

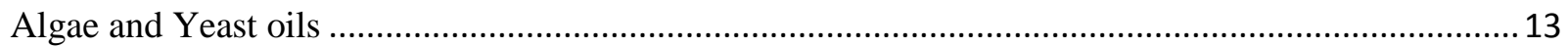

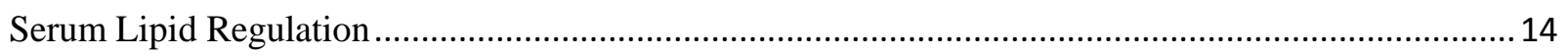

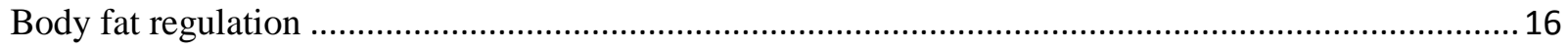

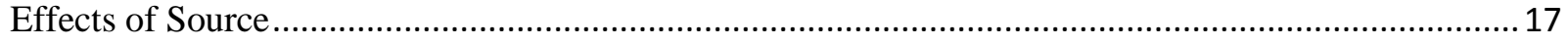

Chapter 2: Absorption of Marine vs Non-Marine sources of EPA and DHA........................................ 18

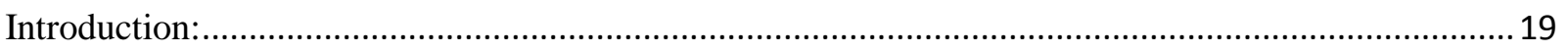

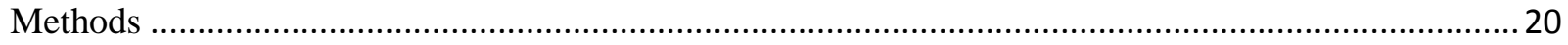

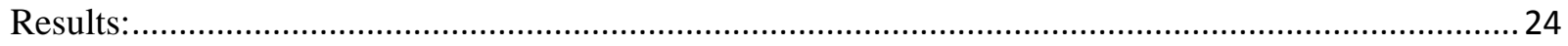

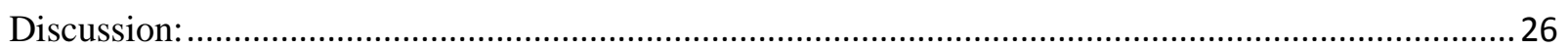

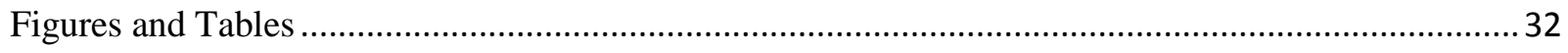

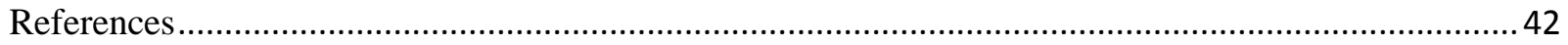




\section{List of Figures}

Figure 1: Hydrolysis Reaction of Pancreatic Lipase

Page Number

Figure 2: Chylomicron Formation $\quad 34$

Figure 3: Effect of Dietary Treatment on Muscle Fatty Acids

A. Muscle EPA Fatty Acid Percent

B. Muscle DHA Fatty Acid Percent

Figure 4: Effect of Dietary Treatment on Adipose Tissue Fatty Acids

A. Adipose EPA Fatty Acid Percent

B. Adipose DHA Fatty Acid Percent

Figure 5: Effect of Dietary Treatment on Fecal Fatty Acids

A. Fecal EPA Fatty Acid Percent

B. Fecal DHA Fatty Acid Percent

Figure 6: Thin Layer Chromatography Picture of Oil 


\section{List of Tables}

\section{Page Number}

Table 1: Composition of diets 33

Table 2: Fatty Acid Composition of Dietary Oils 34

Table 3: Mice Composition Data 35

Table 4: Positional Analysis of Fatty Acids in Dietary Oils 40 
Chapter 1: Review of Literature 


\section{Introduction}

Omega-3 fatty acids have been widely studied for their beneficial effects on cardiovascular disease (CVD) and the metabolic syndrome. The leading cause of death in the US is CVD, and the metabolic syndrome is becoming a bigger concern throughout the world [1]. The omega-3 fatty acids, eicosapentaenoic acid (EPA) and docosahexaenoic acid (DHA), have been reported to lower risk factors for the metabolic syndrome [2]. These beneficial effects include lowering serum triglycerides (TG), improving cholesterol levels, and decreasing body fat. Different sources of omega-3s can have differing effects on the body, even though they contain equal amounts of omega-3 fatty acids [3], including differences in incorporation and eicosanoid production. Differences in the position of fatty acids on the TG could be a possible explanation for these differences between different sources, which could play a role in affecting the lipid digestion, absorption, and transport [4].

\section{Lipid digestion}

Hydrolysis of TGs starts with lingual and gastric lipase [5]. Lingual and gastric lipases start hydrolysis before TGs reach the small intestine, however this hydrolysis accounts for only $10-30 \%$ of TG digestion [6]. Cholecystokinin, synthesized by I cells in the duodenal mucosa, is released in the duodenal and jejunal mucosa in response to the presence of lipid and amino acids in the lumen, and it is the primary hormonal drive for release of pancreatic lipase [7]. Cholecystokinin is also responsible for stimulation of the gallbladder, along with relaxation of the sphincter of oddi and subsequent release of bile acid into the small intestine. Secretin, released in response to lowered $\mathrm{pH}$, acts on a receptor on the pancreas to increase cAMP in the pancreas which leads to bicarbonate release. Bicarbonate is important to regulate the $\mathrm{pH}$ of the small intestine to counter the acidic contents from the stomach [6]. Secretin also enhances the effect of cholecystokinin in the release of enzymes from the pancreas [7].

Pancreatic lipase, the main enzyme involved in TG digestion, acts at the oil-water interface instead of penetrating the micelle [8]. Reaction velocity depends on micellar surface area; therefore 
degree of emulsification is a key component for fat digestion [9]. Bile salts are important for lipid digestion, emulsification of the lipids, and helping to create the mixed micelles. People with decreased bile acid concentrations have decreased lipid absorption [10]. Lipase alone does not have a bile salt requirement for activity, and even is inhibited by bile salts $[11,12]$. The bile salt will displace lipase, at the oil-water interface, into the aqueous phase. Inhibition also results from a buildup of a detergent layer from the bile salts which blocks lipase interaction with the lipids [11]. Lipase inhibition is overcome by interactions of colipase with lipase [13]. Colipase is not essential for lipid digestion, but plays a critical role, and colipase deficiency will cause a decrease in lipid absorption, especially in high fat diets [14]. Lipase and colipase together will create a lipase-colipase-bile salt micelle complex $[15,16]$, and the formation of the complex determines the adsorption of the lipase-colipase complex [17]. Colipase will act as an anchor for the lipase; colipase penetrates the lipid layer and anchors the lipase to the lipid layer [18].

The structure of human pancreatic lipase was established by using cDNA clones after isolation from the human pancreas cDNA library and mature human pancreatic lipase is a glycoprotein with 449 amino acids and a molecular weight of 49,558Da [19]. Pancreatic lipase was shown by crystallography to contain a globular $\mathrm{N}$-terminal domain, formed by a central $\beta$-sheet core, and a C-terminal domain with a $\beta$-sheet sandwich, and stabilized by 7 disulfide bonds [20]. A surface loop is formed by a disulfide bridge between two cysteine residues, and it covers the active site. The loop forms van der Waals bonds with two $\beta$-loops, the $\beta-5$ loop and the $\beta-9$ loop [20]. Colipase binds to the C-terminal domain of lipase [21]. In the absence of mixed micelles, the lid domain remained closed and the active site shut [22]. When micelles are present, there is a conformational change in lipase as the $\beta 5$ loop hinges back away from the $\beta 9$ loop. This change reveals the active site and creates an electrophilic region with phenylalanine and leucine, known as the oxyanion region [23]. Once open, colipase forms two new hydrogen bonds with lipase to stabilize the open conformation [23]. Mutations in the Glu15 residue of colipase, which facilitates formation or new hydrogen bonds, show a decrease in lipase activity without a decrease in micelle 
binding, suggesting that colipase is required not only for binding of lipase to the micelle complex but also to stabilize the structure [24].

The catalytic site of pancreatic lipase has been shown, using the crystal structure [25] and site mutations [26], to have a catalytic triad of action very similar to proteases, with the serine residue following the same motif of proteases. It has 3 conserved amino acids of action in serine, histidine, and aspartic acid; however, it has been reported in some lipases that aspartate is not always conserved and can be substituted by glutamate [27]. The active site is buried under the long loop lid region of the lipase, and this site is exposed once the lid is open [25].The fatty acid binding site is located on top of the central $\beta$ sheet and surrounded by a hydrophobic region [28]. The mechanism of action of lipase has been analyzed and is very similar in most species [29, 30]. Aspartic acid forms a hydrogen bond with histidine and increases the $\mathrm{pKa}$ of the imidazole nitrogen of histidine. This increase turns the histidine into a powerful base facilitating the deprotonation of the serine. This deprotonation allows the serine to act as a nucleophile, and consequently, it attacks the ester carbonyl group on either the sn-1 or sn-3 fatty acids of the TG. This reaction creates a negatively charged tetrahedral intermediate which is stabilized by the oxyanion hole. This oxyanion hole is created with threonine, or phenylalanine in human pancreatic lipase [20], and leucine. The carbonyl reforms with the glycerol acting as a leaving group. A water molecule then donates a proton to histidine and creates a hydroxyl anion. This hydroxyl group then attacks the carbonyl carbon of the lipid which makes another negatively charged tetrahedral intermediate, which is also stabilized by the oxyanion hole. After the carbonyl is reformed the serine is released, and the products diffuse away (Figure 1).

\section{Fatty Acid and Monoglyceride Uptake into Enterocytes}

The pKas of most long chain fatty acids (LCFA) are less than 5, so most of them are ionized at physiological $\mathrm{pH}$ [31]. A folded conformation of unsaturated fatty acids facilitates their rotation into the membrane; although, protonated LCFA's can easily cross the membrane [32]. A key component of lipid 
absorption is the unstirred water layer that lines the brush border membrane. Water molecules are trapped by a network of mucus and glycocalyx in a layer that is $50-500 \mu \mathrm{m}$ [33]. The key aspect of the unstirred water layer is a low $\mathrm{pH}$ that is generated by an $\mathrm{H}^{+} / \mathrm{Na}^{+}$antiport exchange in the brush border membrane $[34,35]$. Since LCFAs need micelles to be in an aqueous environment, fatty acids travel through this water layer in micelles [36]. Once the LCFAs reach a pH in the microenvironment of the water layer that is lower than their pKa they become protonated. This protonation of the LCFAs induces their release from micelles near the microvilli [37]. Also, in the protonated form, LCFAs diffuse easier across the membrane because of greater membrane permeation $[38,39]$. The rounded surface of the microvilli creates a favorable environment for the flip-flop of LCFAs in the membrane [32, 40]. Passive diffusion occurs in three steps; adsorption of LCFA's to the membrane surface, a flip-flop action from the external to internal portion of the bilayer, and desorption from the internal bilayer into the vesicle [41, 42]. The desorption step was shown to be thermodynamically favorable and very fast [42, 43]; albeit, there is controversy regarding whether or not the flip-flop step is rate limiting $[38,40]$.

Absorption of 2-monoglycerol (2-MG) has not been as extensively studied as absorption of LCFAs, and the mechanism is still controversial. Schulthess et al. [44] reported that rate of absorption into isolated enterocytes exhibited passive diffusion and agreed with the adsorption and diffusion mechanism seen with LCFAs. However Murota et al. [45] and Shiu-Ying et al. [46] reported in Caco-2 cell lines, that absorption of 2-MG is also facilitated by protein carriers. These two studies found that the apical membrane has a higher affinity for 2-MG than for LCFA. The 2-MG can undergo interesterification of the fatty acid to sn-1 or 3 positions [47]; the 2-MG pathway is the main pathway in fat absorption [48].

\section{Triglyceride Repackaging}

Below the microvilli is an area called the terminal web that leads into the apical cytoplasm where organelles involved in lipid transport, such as the endoplasmic reticulum (ER) and Golgi complex, are 
located $[49,50]$. The ER is made up of smooth (SER) and rough (RER) structures. The RER appears as lines of membranes studded with ribosomes, and the SER is interspersed around the RER and mitochondria [51]. The Golgi is composed of stacks of parallel sacs consisting of small vesicles on the immature face and large vacuoles on the mature face [52]. After a lipid rich meal, lipid will accumulate in small vesicles of the SER in the apical cytoplasm and also in the larger Golgi vacuoles that are derived from the Golgi saccules [49, 50].

The steps to re-esterify free fatty acids and 2-MGs back into TGs require the action of a fatty acyl CoA ligase, located in the microsomal fraction, to make fatty acyl CoAs [53]. One such ligase is Fatty Acid Transport Protein 4 (FATP4), which exhibits acyl CoA synthetase activity [54] and traps fatty acids in the cell with the CoA group, and it is localized in the ER [55]. Fatty acid binding proteins (FABP) 1 and 2 are expressed in the small intestine [56]. These FABPs are involved with delivering fatty acids to the membranes of the organelles involved with fatty acid transport [57]. While FABP1 can bind to two LCFAs and other hydrophobic molecules, FABP2 is more restricted to one LCFA [58, 59]. Cistola et al. [60] hypothesized that FABP1 transports mainly 2-MG and cholesterol, while FABP2 transports fatty acids. The mechanism of delivery between the two proteins is also different; FABP2 has a collision mechanism involving ionic interactions, and FABP1 uses a diffusion mechanism [61].

Fatty acyl CoAs react with 2-MG to form a diacylglycerol (DG), and this reaction is catalyzed by monoglyerol acyltransferase (MGAT); MGAT2 and MGAT3 are expressed in the human intestines [62] [63]. Once DG is formed, another fatty acyl CoA will react to form TG, catalyzed by diacylglycerol acyltransferase (DGAT) [64]; DGAT1 and DGAT2 are expressed in the small intestine. The 2-MG pathway for TG re-synthesis occurs in the SER [65], and DGAT1 is the major DGAT enzyme for synthesis of TG in the small intestine [66]. This enzyme is localized in the ER membrane and the active site faces the ER lumen whereas DGAT2 is located in the cytosolic side [67]. The DGAT1 pathway is mostly used for TG synthesis in chylomicron secretion, while DGAT2 is used primarily to increase TG storage in the enterocyte and not for chylomicron secretion. The differences in function of DGAT1 and 
DGAT2 were demonstrated in an experiment by Yamazaki et al. [68]; in the liver, overexpression of DGAT1 increased lipoprotein secretion while DGAT2 overexpression led to TG accumulation in the cytosol. DGAT1 is non-essential to lipid absorption for knockout mice suggesting compensation from DGAT2; however, on a high fat diet, the knock out model accumulated lipid in the enterocytes and exhibited a decrease in chylomicrons [69]. Proteins containing carnitine palmitoyltransferase (CPT) activity have been isolated from the ER [70]. Evidence suggests that CPT plays a role in transporting fatty acyl CoAs into the SER, with inhibitors of CPT decreasing lymph TG after a lipid load [71].

\section{Chylomicron Formation}

Once the TGs are resynthesized in the SER, they need to be packaged into chylomicrons for transport (Figure 2). Microsomal triacylglycerol transfer protein (MTP) is expressed in the small intestine, specifically the ER, and it is vital to lipid transport [72]. The three functional domains contained inside MTP allows it to adsorb with TGs and other neutral lipids, interact with the ER membrane, and bind apolipoprotein B48 (ApoB48) [73]. Nascent apolipoprotein, synthesized in the RER, translocates into the SER and binds to TGs before translation of ApoB48 is complete [74]. Wu et al. [75] demonstrated that MTP and ApoB48 interact with each other. This same group also demonstrated that lipids are key in the binding of MTP to ApoB48, where lipid bound MTP associates with ApoB48 up to 5 fold more than without lipid. Association with ApoB48 facilitates MTP's folding into its mature state [76]. In the SER, MTP binds and shuttles TGs, for which it has the greatest affinity compared to other lipids [77]. Inhibition or a deficiency in MTP decreases TGs in the ER lumen and reduces ability of enterocytes to secrete ApoB48 and lipoproteins [78, 79]. If ApoB is not associated with lipid bound MTP, then it proceeds through a proteasomal degradation pathway. The ApoB translocates out of the ER, and it is ubiquinated and targeted for degradation [80, 81].

Lipid droplet formation happens in the ER lumen prior to incorporation into lipoproteins. The transport of TGs, synthesized by DGAT1, is facilitated by MTP from the membrane into lipid droplets in 
the lumen [82]. Lipid droplet fusion and its incorporation into lipoprotein particles is promoted by MTP [79]. The lipid droplet accumulates TGs in the SER and will fuse with ApoB from the RER [83]. To stabilize the lipoprotein, apoAIV is incorporated, and this apoprotein is correlated with lipid absorption from the diet [84]. Mansbach and Nevin [85] showed that export from the ER into the Golgi is a rate limiting step in TG transport. The lipoprotein buds and forms a pre-chylomicron transfer vesicle (PCTV), where FABP1 is involved in SER membrane deformation, leading to this process [86]. The membrane protein cluster of differentiation 36 (CD36) has also been implicated in playing a role in the budding of the PCTV from the SER [87]. The PCTV contains an exclusive protein, vesicle-associated membrane protein-7, that targets the PCTV for the Golgi membrane [88]. Coatomer II proteins (COPII) are required for the PCTV to reach and interact with the Golgi, specifically Sec24C and Sec23; these proteins are associated with the PCTV until fusion with the Golgi [89]. The COPII protein Sar1b associates with the Golgi for which it is required for fusion of the Golgi membrane with the PCTV and its subsequent uptake [90]. In the absence of these COPII, the PCTV cannot target and fuse with the Golgi [91].

Once PCTV fuses with the Golgi, it dumps its contents into the Golgi lumen. Once in the Golgi, more processing of the lipoprotein occurs. More apolipoproteins are added to the pre-chylomicron, specifically ApoAI [88]; additionally ApoB48 is glycosylated [92]. Vesicles transport the chylomicron in the Golgi to the basolateral membrane; these vesicles are released, by reverse exocytosis, into intracellular space to the lamina propria [93]. The lacteal, which takes up the chylomicrons into the lymphatic system, is located centrally in the core of the lamina propia [94]. Transport and uptake of chylomicrons into the lacteal are a topic of much debate. Two conflicting models are 1) paracellular transport by open junctions in the lacteal $[95,96]$ and 2) transcellular transport using closed junctions $[97,98]$.

\section{Chylomicron transport through the lymph}

Once the chylomicron has been taken up by the lacteal, it is transported throughout the body by the lymph system. Hydration affects transport rates of chylomicrons into the lymphatic system, with 
lymph flow rate and chylomicron appearance in lymph decreased by dehydration [99]. Lymph rate also increases when lipid is ingested [100]. The capillaries of the lymphatic system are composed of single layer endothelial cells [101]. Mice that had genetic defects in their lymphatic vasculature became obese [102]. These same mice showed greater deposition of subcutaneous fat. This observation may be due to leaky lymph vessels, where lymph was shown to increase differentiation of adipocytes in vitro [102]. Lymphatic vessels merge into collecting vessels called lymphangions that are lined with smooth muscle, which allows then to contract [103]. Lymph is transported against the pressure gradient formed and eventually dumped into the thoracic duct to enter the circulatory system.

\section{Lipoprotein Lipase; Structure, Action, and Regulation}

Lipoprotein lipase (LPL) is one of the primary enzymes for lipid uptake into tissues. It is expressed in many tissues throughout the body, mainly ones that use or store fatty acids such as cardiac, skeletal muscle, and adipose tissue [104]. Synthesis of LPL occurs in the parenchymal cells of tissues, and its transported as a homodimer to the luminal surface of vascular endothelial cells. LPL is transported to the endothelial cells by way of the glycosylphosphatidylinositol-anchored high-density lipoproteinbinding protein 1 (GPIHBP1) [105]. Defects in GPIHBP1 will cause LPL to stay in the parenchymal cells and cause chylomicronemia [106]. Ion interactions with heparin sulphate-proteoglycans and glycosyl phosphatidylinositol anchors LPL to endothelial cells [107]. The size of human LPL is about 67,000 Da [108]. LPL has two structural domains - an amino-terminal domain that contains its catalytic site, and a carboxyl-terminal group that contains its heparin binding site [109].

The catalytic site of LPL is very similar to that of pancreatic lipase. It has a serine-aspartatehistidine catalytic triad, a lid region, and an oxyanion hole stabilized with tryptophan and leucine [109]. The cofactor apoC-II, which binds the N-terminal domain, is needed by LPL to become fully active [110]. The cofactor for LPL, apoC-II, is found on the surface of lipoproteins. Patients with a defect of the apoC- 
II gene are hypertriglyceridemic [111]. The activity of LPL is greatly decreased in the absence of apoC-II [112].

Regulation of LPL is tissue specific; fasting will increase levels of LPL in muscle tissue while decreasing levels in adipose tissue [113]. The site with the highest amount of LPL is in heart muscle where its used to provide fatty acids for oxidation. Cardiac LPL has an inverse regulation relative to adipose LPL [113]. In adipose tissue, LPL is downregulated when in a fasting state with a decrease in activity, and upregulated in a fed state $[114,115]$.

An increased expression of LPL is seen by apoAV, which leads to a decrease in TGs; an apoAV deficiency causes hypertriglyceridemia [116]. Cyclic AMP-responsive element-binding protein $\mathrm{H}$ (CREB-H) induces several genes that influence LPL. In a study by Lee et al. [117], mice with a knockout of the CREB-H controlling gene, CREB3L3, showed high TG levels, higher levels of the LPL inhibitor apoCIII, and higher amounts of TGs in very low density lipoproteins (VLDL) compared to control mice. Overexpression of CREB-H in mice was associated with increases in apoCII and apoAIV, activators of LPL. Patients with hypertriglyceridemia exhibited defects in the CREB3L3 gene that were non-existent in normolipidemic patients [117]. Insulin will increase LPL gene transcription [118]. Glucose also regulates LPL activity, post-translationally, with its major regulatory effects being glycosylation of the LPL enzyme that is essential for its activity [119]. Peroxisome proliferator-activated receptors (PPAR), specifically PPAR $\alpha$ and PPAR $\gamma$, are activators of LPL, where activation PPAR $\alpha$ and PPAR $\gamma$ upregulated LPL in liver and adipose tissue, respectively [120]. An inhibitor of LPL, apoC-III, is down regulated by PPAR $\alpha$ [121]. Khan et al [122] demonstrated that supplementing FO in moderate hypertriglyceridemic men increased adipose LPL levels and LPL mRNA, which would be a factor in lowering serum TG levels. 


\section{Uptake of Fatty Acids and 2-Monoacylglycerols}

While intestinal LCFA uptake is mostly by diffusion, there is evidence that uptake into other cells is protein facilitated [123, 41]. Flip flop rates of LCFA across the plasma membrane are be slow because the membrane presents a barrier for uptake [124]. LCFA enter into the cells via CD36, which has been identified as a fatty acid translocase (FAT) for LCFA uptake [125]. Mice deficient in CD36 have impaired LCFA uptake in heart, muscle, and adipose tissue with elevated fasting levels of plasma TGs and LCFA's [126]. In muscle, CD36 is upregulated by insulin and contractions [127] and it is also activated by PPAR $\delta$ [128]. Forkhead box protein O1 (FOXO1) stimulates recruitment of CD36 to the plasma membrane to enhance FA uptake [129]. Also expressed with CD36 are FATP1 and FATP6, which have transportation properties across the cell membrane, as well as their acyl-CoA synthetase properties [130].

In order to transfer between intracellular membranes, LCFA must bind to FABP [131]. The main FABP in muscle tissue is heart-FABPc that transports fatty acids to the mitochondrial membrane where an acyl-CoA synthetase converts it to a fatty acyl-CoA [132]. CPT-I then will convert fatty acyl-CoA to a fatty acyl-carnitine for transport into the membrane via carnitine transporters [133]. The fatty acyl-CoA will be regenerated once across the membranes and will undergo oxidation for energy in the mitochondria. The LCFA can also be resynthesized into TGs and stored in the cells, mostly in adipose tissue. The reaction, described by Bell and Coleman [134] and Stam et al. [135], starts with glycerol 3phosphate which reacts with the fatty acyl-CoA; this reaction is catalyzed by glycerol-3-phosphate acyltransferase. After 2 fatty acyl-CoAs are attached to form phophatidic acid, phosphtidic acid phosphatase removes the phosphate group. The last reaction is catalyzed by DGAT; fatty acyl-CoA is attached on the existing diacylglycerol to form a TG. 


\section{Metabolic syndrome}

Excessive lipid consumption and storage can lead to obesity and increase risk factors for the metabolic syndrome [136]. Metabolic syndrome is a classification for individuals at risk for CVD and diabetes. Its prevalence is becoming wide spread worldwide [1]. Metabolic syndrome is defined different ways by different organizations, but the main risk factors included are high TGs, increased blood pressure, reduced high density lipoprotein (HDL), and a larger than normal waist circumference [137]. The leading cause of death in the USA, accounting for over a third of deaths, is CVD [138]. Omega-3 fatty acids, specifically EPA and DHA, are used as treatment and preventative options for patients at risk of CVD. Most people do not consume enough omega-3s in their diets with average consumption of EPA and at DHA $0.05 \mathrm{~g} /$ day and $0.10 \mathrm{~g} /$ day, respectively, while the American Heart Association recommends, for patients with CVD $1 \mathrm{~g} /$ day each, or 2-4 g/day in patients with high TGs [139].

\section{Omega-3 Sources}

The primary dietary polyunsaturated omega-3 fatty acids (PUFAs) are $\alpha$-linolenic acid (ALA), EPA, and DHA. Because humans do not make the $\Delta-12$ desaturase enzyme necessary to synthesize PUFAs, it is important to get adequate amounts of these PUFA's in the diet. High intake of PUFAs, specifically from fish, has been attributed to a decrease in mortality from coronary heart disease [140].

Most plant sources do not contain high amounts of EPA or DHA, but rather ALA. The PUFAs that are contained in fish, mainly EPA and DHA, are derived from consuming plankton and [141]. ALA can be found in high amounts in vegetable products, especially nuts and seeds, including flax, walnuts, and chia and also green leafy vegetables [142]. Vegetarian and vegan diets are normally very low in EPA and DHA; however, ALA is usually high in these diets [143]. Non-marine sources of DHA and EPA are on the market; these sources include algal and yeast oil. Vegetarian, vegan, and meat-eating subjects were compared for plasma fatty acids, and subjects consuming vegetarian and vegan diets were had decreased EPA and DHA levels [144]. The $\Delta-6$ desaturase enzyme is involved with converting linoleic and linolenic 
acid to more unsaturated fatty acids, and coupled with elongase, produce arachidonic acid or EPA, respectively. These pathways share the same enzyme so there is competition between the two. These enzymes are expressed throughout the body, especially in the brain, heart, liver, lung, and somewhat in muscle [145]. However the conversion from ALA is low, and usually less than 5\% [146]. A meta-analysis conducted in humans supplemented with ALA, subjects showed minimal increases in EPA and no increases in DHA [147]. In a study comparing DHA incorporation into rat hearts from ALA and DHA supplementation, ALA supplemented rat hearts contained 6\% more DHA(10\%) than controls (4\%), but $10 \%$ less than DHA supplemented diets (20\%) [148]. ALA supplementation effectively decreases CVD risk factors; ALA supplementation with flaxseed decreased serum TGs by $36 \%$ and improve the LDL:HDL ratio in hyperlipidemic patients [149]. This supplementation lowered LDL in healthy patients by $8-18 \%[150,151]$. However, there has also been work done showing that ALA is not as effective as EPA or DHA; in fact supplementation of ALA with overweight patients showed no effects on lipid levels [152].

\section{Algae and Yeast oils}

DHA from algae oil, produced primarily from Crypthecodinium cohnii, is used widely as an alternative to fish oil, with its most common uses in infant formula, pill supplements, and fortified foods; it has been labeled as Generally Recognized As Safe from the Food and Drug Administration [153]. Supplementation with AO in hypertriglyceridemic men decreased TGs by $24 \%$ with an increase in size of LDL particles and decreased particle number [154]. In a study with menopausal women, Stark and Holub [155] found a $20 \%$ decrease in TG and an $8 \%$ increase in HDL, with no change in LDL. In contrast, Theobald et al [156] supplemented middle aged men and women with low dose DHA capsules and detected increased LDL and total cholesterol, with no decrease in TG levels.

Although not widely used, yeast oil supplements that are derived from the Yarrowia lipolytica, are on the market that are enriched in EPA. There have not been many studies conducted examining the 
effects of YO. In a rat model, different dosages of EPA from YO, FO and YO showed similar effects in decreasing cholesterol [157]. Another study from the same group tested YO in a similar model but with a longer testing period and detected decreased total cholesterol in YO-fed rats compared to control, but only in a higher dosage [158]. No differences in TGs were observed in any of the groups compared to the control in these studies.

\section{Serum Lipid Regulation}

Decreasing levels of LDL reduce atherosclerosis by decreasing the amount of fatty streaks that occur in the capillaries [159]. Evidence suggests that EPA and DHA can increase HDL [160]; however, this effect is debatable. Patients with hypercholesterolemia, supplemented with EPA over 4-6 years, saw a decrease in LDL levels by $25 \%$, and a resulting $19 \%$ decrease in major coronary events compared to control patients [161]. Mice fed FO exhibited a down regulation of LDL receptor gene expression in hepatic tissues [162]. Patients with type-2 diabetes given EPA and DHA showed an increase in HDL and reduced VLDL [163]. However, there have been mixed results on the effects of EPA and DHA on LDL levels; some studies found no change when compared to controls, as demonstrated by Skulas-Ray et al [164] where supplementation of FO in healthy moderately hypertriglyceridemic patients showed no change in LDL levels.

The effect of FO and concentrated EPA/DHA supplementation on serum TG levels has been extensively studied. Fish oil supplementation is used pharmacologically in patients with severe hypertriglyceridemia to help lower TG levels [164]. In an observational study that evaluated overweight patients with type 2 diabetes, fish consumption was negatively correlated with serum lipid levels and showed an inverse relationship with TG levels [165]. In patients with type-2 diabetes, EPA and DHA supplementation reduced TGs [163]. In a study with moderate hypertriglyceridemic patients, low doses of FO supplementation did not reduce TG levels; however, with high doses of $3.4 \mathrm{~g} /$ day of EPA+DHA, TGs were lowered by $27 \%$ [164]. 
One of the primary TG synthesis regulators is transcription factor sterol regulatory elementbinding protein 1c (SREBP1c), that stimulates synthesis of lipogenic genes involved in TG synthesis. Once synthesized, TGs are packaged into VLDL and secreted into circulation [166]. In the ER membrane, SREBP1c is synthesized as a precursor protein. Sterol deficiency stimulates sterol-regulatory element binding protein cleavage-activating protein to move SREBP1c to the Golgi where proteolytic cleavage of SREBP1c allows the mature protein to translocate to the nucleus, bind to sterol response elements, and induce gene transcription [167]. PUFAs decrease SREBP1c transcription, which is regulated by Liver X Receptor (LXR) [168]. To stimulate SREBP1c transcription, LXR will heterodimerize with Retinoid X Receptor (RXR) and will bind to a response region in the promoter of the SREBP1c gene. PUFAs can bind to LXR, which will inhibit LXR binding to this region, thus suppressing stimulation of SREPB1c by LXR [169]. In mice fed a high fish oil, diet SREBP-1c protein levels were decreased by $57 \%$ in response to decreased SREBP1c mRNA (-86\%) levels in the liver compared to controls [170]. DHA prevented LXR activation of SREBP1c transcription [171]. Also DHA regulates SREBP1c by proteosomal degradation of nuclear SREBP1c [172].

Numerous other genes are regulated by LXR, including Cyp7x, LPL, SCD1, and sterol transporters including the ATP-Binding Cassette gene family ABCA1 and ABCG5/G8 [173]. Oxysterols are the primary agonist for LXR, and binding of LXR to them will increase gene transcription for LXR targeted genes [169]. PUFAs interact with the receptor on LXR for oxysterols and act as an agonist. Cells treated with LXR agonist in PUFA media had a reversal of the inhibitory effects of PUFAs [174]. However Pawar et. al. [168] demonstrated, in a rat model, that genes involved with LXR regulation and that did not require SREPB1c interaction were unaffected after FO feeding.

PPARs are nuclear receptors that function as ligand-activated (such as PUFAs) transcriptional regulators of genes which control lipid and glucose metabolism [175]. A main regulator of lipid homeostasis, PPARa, regulates genes including CPTI and CPTII, LPL, and uncoupling protein I (UCPI) [176]. Also regulated by PPARs are LXRs, which will diminish their lipogenic effects [177]. Omega-3 
PUFAs affect PPAR $\alpha, \delta$, and $\gamma$; however, their metabolites, specifically eicosanoids, are much more potent activators, especially for PPAR $\alpha$ [178].

\section{Body fat regulation}

Rats fed a high fat diet ( $48 \%$ of calories), with $15 \%$ consisting of FO, exhibited decreased subcutaneous and visceral adipose tissue weights when compared with a high fat control [179]. Rats fed a $20 \%$ FO diet had a reduction in size of adipocytes with no reduction in number compared to $20 \%$ lard control [180]. Ruzickova et al. [181] observed decreased epididymal fat in mice fed high fat diets (35\% by weight) containing EPA and DHA with limited effect on subcutaneous fat compared to control. In their study, the anti-adiposity effect was promoted by a lower EPA/DHA ratio. Mice that were fed a high FO diet (32\% weight) after reaching an obese state on control (32\% fat by weight) lost $24 \%$ bodyweight after 6 weeks [182]. Reduction in adipose weights for rats fed FO diets was attributed to a reduction in adipocyte hypertrophy, and a dose dependent reduction of lipid mass from FO [183].

Carnitine palmitoyltransferase I is an enzyme used to shuttle fatty acids into mitochondria for oxidation. CPT-I is increased in rat skeletal and cardiac muscle when animals intake FO compared to an olive oil control [184]. AMP-activated protein kinase (AMPK) is a regulator of CPT-I, it is activated by EPA in adipose and skeletal muscle [185, 186]. Supplementation of PUFAs increase uncoupling protein-3 (UCP) in skeletal muscle; UCP3 is less efficient than mitochondrial oxidation for usage of substrates for ATP $[187,188]$. In a study by Flachs et al. [189], mice were fed a high fat diet of flaxseed high in ALA or flaxseed mixed with EPA and DHA. Mice fed the EPA/DHA diet had less epididymal fat than the flaxseed-fed mice. They also exhibited increases in CPT-I and nuclear respiratory factor-1, a promoter for mitochondrial synthesis [190], in the epididymal fat but not in the subcutaneous fat. 


\section{Effects of Source}

Although ALA is an essential fatty acid and can be converted to EPA and DHA, supplementary and dietary EPA and DHA are more effective than ALA in terms of cardio protective effects. Body fat and cholesterol decreases are not observed with ALA; however, it has shown some similar effects in lowering serum TG levels [191]; whereas other studies have shown ALA supplementation ineffective at lowering TG levels [192]. EPA and DHA are equally effective in increasing the clearance rate of dietary TGs [193]. EPA and DHA also have similar effects in lowering serum TGs [193]. One difference between PUFAs is that DHA can increase HDL cholesterol concentrations, while EPA and ALA do not [194]. While both EPA and DHA lower serum TG levels, some studies have shown that DHA can be more effective [195]. Differences in effects on nuclear receptors have been noticed in some studies. EPA is a more potent activator of PPAR $\alpha$ [196] and PPAR $\delta$ [197]. EPA and DHA reduce SREBP1c mRNA, but DHA is more effective with longer lasting effects [172]. However DHA reduces the nuclear presence of SREBP1c protein while EPA did not [172].

Different sources of omega-3 fatty acids could influence absorption of omega-3s from the diet. When fed equal amounts of DHA in the diets, AO was less effective in lowering serum TG than FO [198]. AO-fed mice required twice the amount of dietary DHA to elicit the same amount of DHA incorporation into tissues as FO-fed mice [199]. These differences could possibly be due to differences in the oils; specifically the positional differences on the TGs. Yoshida et al. [3] showed that seal oil containing diets, which has asimilar fatty acid content as FO, had less EPA and DHA recovered in lymph compared to FO containing diets when fed to rats. The main difference between FO and seal oil is that EPA and DHA are mostly localized at the sn- $1 / 3$ position in seal oil while they are primarily at the sn-2 position for FO. 


\section{Chapter 2: Absorption of Marine vs Non-Marine sources of EPA and DHA}

Authors: JS Ketz, MC Rodavich, SD Slider, PB Kenney, KM Barnes

Division of Animal and Nutritional Sciences

West Virginia University, Morgantown, WV 26506 


\section{Introduction:}

With the widespread prevalence of metabolic syndrome and cardiovascular disease (CVD), the leading cause of death in the United States [138], there has been much interest to find preventative measures. Metabolic syndrome is usually classified as patients with high serum triglycerides (TGs), increased blood pressure, and reduced high density lipoprotein (HDL) [137]. Polyunsaturated fatty acids (PUFAs), specifically the omega-3 fatty acids eicosapentaenoic acid (EPA) and docosahexaenoic acid (DHA), are being used as treatment and preventative measures for patients at risk of CVD and with high TGs [2]. The primary source for these omega-3s is fatty fish and fish oil (FO). FO supplementation decreases low density lipoprotein (LDL) levels while decreasing CVD risk [161]. FO also decreases serum TG levels in patients $[163,164]$.

Alternative sources to FO have been investigated for sustainability and vegetarian reasons. Algae oil (AO) from Crypthecodinium cohnii is now a common source of DHA, and it is used for DHA supplementation in infant formula [153]. AO supplementation decreases serum TG [154, 155] while also lowering LDL levels compared to an olive oil control [154]. Although not very common, yeast oil (YO) from Yarrowia lipolytica is an alternative for EPA supplemention. Few investigations on the effect of YO have been conducted, although it has been shown to decrease cholesterol levels in a rat model [158].

Previous studies from our lab showed marked differences in tissue fatty acid composition of DHA and in serum lipid levels between FO and AO-fed mice. When mice were fed equal amounts of dietary DHA, FO-fed mice had a greater decrease in serum triglycerides and total cholesterol than the AO-fed mice [198]. AO-fed mice required 3.5-5 times as much dietary DHA to cause a similar reduction in serum cholesterol [199]. AO-fed mice fed twice the dietary DHA as FO-fed mice had the same percentage of DHA incorporation into tissues [199].

This study explored the reasons why AO-fed mice had less DHA incorporation into tissues than FO-fed mice. We also used YO to compare the effect of EPA vs DHA. We therefore tested the hypothesis 
that absorption of omega-3 fatty acids in different by measuring percent of lipid in fecal samples of mice fed FO, YO, and AO. Lipid classes of the oils were measured as well as positional distribution of the omega-3 fatty acids on the triglycerides in the oils.

\section{Methods}

\section{Research design}

All animal procedures were conducted in accordance with an approved Institutional Animal Care and Use Committee protocol. All diets were based on the AIN-93G diet with soy isolate as the protein source and 12\% lipid (Table 1). Menhaden Fish oil (FO) (Dyets Inc., Bethlehem, PA), Algal vegetable oil from Crypthecodinium cohnii (AO) (Martek Biosciences Corp., Columbia, MD), and Yeast oil from Yarrowia lipolytica (YO) (Futurebiotics Corp., Hauppauge, NY) replaced soy oil (SO) (Dyets Inc.). On a weight/weight basis, these diets provided $7.03 \mathrm{~g} / \mathrm{kg}$ DHA and $/$ or $12.64 \mathrm{~g} / \mathrm{kg}$ EPA, which was the level of DHA and EPA provided by the $12 \%$ fish oil diet (Table 2$)$. Male ICR mice $(n=100)$ were obtained from Harlan Inc. (Indianapolis IN.) and housed individually. They were acclimated to the control soy oil powdered diet for 1 week. Mice were blocked by body weight and randomly assigned to one of 5 treatments. Treatments were SO, FO, AO, YO, or AO + YO. There were 20 mice assigned to each diet. Mice were fed for either a 2 week period or a 4 week period.

Seven mice from each diet assigned to receive the experimental diets for 4 weeks were randomly selected and placed in metabolism cages to collect fecal samples. Once a week for four weeks, mice were placed in metabolism cages overnight and fecal samples were collected and stored at $-20^{\circ} \mathrm{C}$. After 2 weeks, half of the mice from each diet were euthanized, following 5 hours of fasting, and then weighed to determine a final body weight. Mice were killed by $\mathrm{CO}_{2}$ asphyxia and bled via cardiac puncture. Liver, heart, brain, retroperitoneal and epididymal fat pads, and thigh muscle samples were collected and weighed. Samples were put into $2 \mathrm{~mL}$ cryogenic vials (Fisher Scientific, Pittsburgh, PA), flash frozen in 
liquid nitrogen, and stored at $-80^{\circ} \mathrm{C}$. Body fat index was calculated as ((retroperitoneal fat pad + epididymal fat pad)/total body weight)x100.

\section{Muscle and adipose tissue fatty acid extraction}

Muscle $(0.25-0.5 \mathrm{~g})$ and adipose $(0.05-0.1 \mathrm{~g})$ tissues were extracted using the method of Park and Goins [200]. Samples were put into a $10 \mathrm{~mL}$ glass tube, and $200 \mu \mathrm{L}$ methylene chloride and $0.5 \mathrm{M} \mathrm{NaOH}$ in Methanol were added. A $1 \mathrm{ml}$ aliquot of $\mathrm{C} 17: 0$ standard $(0.2 \mathrm{mg} / \mathrm{mL})$ was added, and the tube was flushed with nitrogen gas. Samples were then put into a water bath at $90^{\circ} \mathrm{C}$ for $30 \mathrm{~min}$ and subsequently cooled to room temperature. Two $\mathrm{ml}$ of $14 \%$ boron triflouride, in methanol, was added to the tubes; these tubes were flushed with nitrogen gas, vortexed, and put into a water bath at $90^{\circ} \mathrm{C}$ for $30 \mathrm{~min}$. Samples were then cooled to room temperature, and $2 \mathrm{~mL}$ hexane and $2 \mathrm{~mL}$ water were added. Samples were vortexed and allowed to sit until the phases separated. The hexane layer was transferred, using a glass pastuer pipet to a clean $10 \mathrm{~mL}$ tube to which $1 \mathrm{~g}$ of sodium sulfate was added. The hexane layer was subsequently transferred to a $1.8 \mathrm{~mL}$ clear, screw top GC vial (Chromatograph Research Supplies Inc., Louisville, KY) and stored at $4^{\circ} \mathrm{C}$. A Suplecowax 10 column $(60 \mathrm{~m} \times 0.53 \mathrm{~mm} \times 0.5-\mu \mathrm{m}$ film thickness; Supleco, Bellefonte, PA, USA) was used. Column temperature was $160^{\circ} \mathrm{C}$ for 10 minutes, and then it was increased $5^{\circ} \mathrm{C}$ per minute to $220^{\circ} \mathrm{C}$ and held for up to 60 minutes. Injector temperature was $250^{\circ} \mathrm{C}$, and detector temperature was $260^{\circ} \mathrm{C}$. Fatty acids were identified by retention times compared to mixed fatty acid methyl ester standards (GLC-96, GLC-502, and GLC-455; Nu Chek Prep, Elysian, MN).

\section{Fatty acid extraction and methylation of fecal samples}

Fatty acids were extracted by a modified version of the method described by Bligh and Dyer [201]. Fecal samples (0.05-0.3g) were ground using a mortar and pestle, weighed, and placed in 35-mL Teflon lined screw cap glass centrifuge tubes. One $\mathrm{mL}$ of a C19:1 standard $(0.2 \mathrm{mg} / \mathrm{mL})$ was added to the samples. Five $\mathrm{ml}$ of a Trizma/EDTA solution (50mM Tris HCL, 1mM EDTA-disodium salt) was added and samples were vortexed for $60 \mathrm{sec}$. Twenty $\mathrm{mL}$ of 2:1:0.015 chloroform: methanol: glacial acetic acid 
(vol/vol/vol) were added, and samples were vortexed. Tubes were then centrifuged at $900 \mathrm{~g}$ at $10^{\circ} \mathrm{C}$ for 10min. The lower layer was transferred by glass Pasteur pipet, and filtered through 1-PS filter paper into a new 35-mL Teflon lined screw cap glass tube. Ten $\mathrm{mL}$ of 4:1 chloroform : methanol (vol/vol) was added; the mixture was vortexed for $15 \mathrm{sec}$, centrifuged as before, and then the lower layer transferred over the filter paper again. The 2:1 chloroform:methanol mixture was used to rinse the filter paper and funnel. Tubes were then dried under nitrogen gas on a $60^{\circ} \mathrm{C}$ heating block. To methylate the samples, the method of Fritshe and Johnston [202] was used; four mL of a 4\% sulfuric acid solution, in anhydrous methanol, was added to samples in the $35-\mathrm{mL}$ glass tubes. Samples were then incubated in a water bath at $90^{\circ} \mathrm{C}$ for $60 \mathrm{~min}$, cooled to room temperature, and $3 \mathrm{~mL}$ of deionized distilled water added to stop the reaction. Eight $\mathrm{mL}$ chloroform was added and samples were vortexed for 30sec, then centrifuged as previously described. Each sample was filtered through sodium sulfate, rinsed with chloroform, and collected in a $10 \mathrm{~mL}$ screw cap glass tube. Samples were then dried under nitrogen on a $60^{\circ} \mathrm{C}$ heating block and resuspended in $3 \mathrm{~mL}$ of hexane. The hexane solution, containing the sample, was then transferred to a $9 \mathrm{~mm}$ gas chromatography screw vial (Agilent Inc., Santa Clara, C.A.) and stored at $-20^{\circ} \mathrm{C}$ to be analyzed by gas chromatography. Fatty acid methyl esters were analyzed using a Varian CP-3800 gas chromatograph (Agilent Inc.) with a flame ionization detector. A WCOT fused silica capillary column (100-m length, 0.25-mm inside diameter; Agilent Inc.) was used to separate fatty acid methyl esters. CP-Sil 88 was used as the stationary phase. Nitrogen was used as the carrier gas, and a 10:1 split ratio was employed. Oven temperature was held at $140^{\circ} \mathrm{C}$ for $6 \mathrm{~min}$, then increased to $220^{\circ} \mathrm{C}$, at a rate of $4^{\circ} \mathrm{C} / \mathrm{min}$, and held for $37 \mathrm{~min}$. The total separating time was $63 \mathrm{~min}$. The injector temperature was held at $270^{\circ} \mathrm{C}$, and the detector temperature was $300^{\circ} \mathrm{C}$. Sample fatty acid methyl ester retention times were compared to a standard (Supelco $^{\mathrm{TM}}$ quantitative standard FAME 37; Sigma-Aldrich, St. Louis, Mo.) fatty acid methyl ester retention times for identification. Peak area was computed by an integrator using the Star GC workstation version 6 software (Agilent Inc.). Fatty acid composition was reported as a percentage of total fatty acids identified. 


\section{Thin Layer Chromatography}

Lipid classes of the oils were analyzed using thin layer chromatography. A $10 \mu \mathrm{L}$ sample of oil was dissolved in 1:1 chloroform:methanol (vol/vol) and spotted onto Whatman K6F silica plates with $60 \AA ̊$ pore sizes (Cobert Associates, St. Louis, MO). A 10 $\mu \mathrm{L}$ sample of a TLC standard (TLC 18-5, Nu Chek Prep) was spotted along with the samples as well as a triglyceride and free fatty acid standard (Triolein and Oleic acid, Nu Chek Prep) to compare bands. Plates were put into a mobile phase solvent consisting of a 80:20:1.5 mixture of hexane: diethyl ether :acetic acid solution (vol/vol/vol). The plates ran for 70min until the mobile phase reached the end of the plate. Plates were then air dried for 5min, they were charred for imaging by covering in a $50 \%$ sulfuric acid in-water solution and heated for $45 \mathrm{~min}$. Images were taken using a Fluorchem 8000 densitometer with transluminating white light (Alpha Innotech Corp, San leandro, CA).

\section{Triglyceride fatty acid position}

We followed the procedure of Smith et al. [203], where $40 \mu \mathrm{L}$ of each oil was added to $1 \mathrm{~mL}$ of buffer containing $1 \mathrm{mg} / \mathrm{mL}$ Triton X-100, $0.04 \mathrm{M}$ Tris, and Borate of 0.05M (pH 7.2); reactions were carried out in a $12 \mathrm{mmx} 75 \mathrm{~mm}$ polypropylene disposable tube (Fisher Scientific, Pittsburgh, PA, U.S.A.). Samples were sonicated for $3 \mathrm{~min}$ for complete emulsification. Samples were then transferred to a $35 \mathrm{~mL}$ Teflon lined screw cap glass centrifuge tube, to which 200 units of porcine pancreas lipase (SigmaAldrich, St. Louis, Mo., U.S.A) was added. This lipase was used in lieu of R. arrhizus lipase as described by Smtih et al. A second set of samples were run without the lipase. Samples were then digested for $60 \mathrm{~min}$ at in a $37^{\circ} \mathrm{C}$ water bath. The reaction was terminated by addition of $0.5 \mathrm{~mL} 1 \mathrm{~N}$ acetic acid and 3 $\mathrm{mL}$ chloroform/methanol (2:1 vol/vol). The samples were then separated by TLC plate as previously described without charring to isolate the monoglycerides from the digested samples. The samples were assayed with a monoglyceride standard (Monoolein, Nu Chek Prep, Elysian, MN, USA) to confirm the location on the plate. The monoglyceride fraction from the digested samples and the triglyceride fraction 
from the undigested samples were scraped into a new $35 \mathrm{~mL}$ glass tube. Samples were then methylated according to the Smith procedure [203] by incubating in $1 \mathrm{~mL}, 0.1 \mathrm{~N} \mathrm{NaOH}$ in methanol for 30min at $65^{\circ} \mathrm{C}$. Lipids were extracted using $3 \times 3 \mathrm{~mL}$ hexane, evaporated under nitrogen gas on a $60^{\circ} \mathrm{C}$ heating block, and resuspended in hexane to have $5 \mathrm{mg}$ lipid/mL hexane. Samples were stored in $9 \mathrm{~mm}$, gas chromatography screw vials, and fatty acids were analyzed as previously described.

\section{Statistics}

Data were analyzed by ANOVA testing the main effects of diet and block using the proc mixed procedure, with Pearson correlations analyzed using the proc corr procedure, of SAS version 9.3 (SAS institute Inc., Cary, NC, U.S.A.). No diet $\mathrm{x}$ block interactions were detected so this was removed from the model. Treatment differences were determined by difference of least square means. All data is reported as means \pm Standard Error for all data. $\mathrm{P}<0.05$ was considered significant and trends were noted at $\mathrm{P}<0.10$.

\section{Results:}

\section{Body composition analysis:}

No differences in average daily feed intake or final body weight (Table 3) were detected. There was a trend $(\mathrm{P}<0.10)$ in body fat index for FO- and YO-fed mice to be leaner than AO+YO-fed mice (Table 3). Relative brain weights of YO-fed mice were greater than those of FO-, AO-, and AO+YO- fed mice $(\mathrm{P}<0.05)$ at week 2; however, there was no difference at week 4. Relative liver weights (Table 3) of the FO-fed mice were greater than those of the AO- and SO- fed mice $(\mathrm{P}<0.05)$ at week 2. Relative liver weights of the YO-fed mice were greater than those of the SO-fed mice $(\mathrm{P}<0.05)$ at week 2. At week 4, relative liver weights of the FO-fed mice were greater than those of all the other diets $(\mathrm{P}<0.05)$. diet did not affect relative heart weight (Data not shown). 


\section{Fatty acid composition of tissues}

Muscle EPA percent fatty acids (Figure 3a) was greater at week 2 from FO-fed mice than from mice on other diets $(\mathrm{P}<0.05)$, while the $\mathrm{AO}+\mathrm{YO}$ - and $\mathrm{YO}$-fed mice muscle EPA were greater than AOand SO-fed mice muscle EPA $(\mathrm{P}<0.05)$. At week 4 FO-fed mice had the greatest EPA percent in muscle $(\mathrm{P}<0.05)$, and $\mathrm{AO}+\mathrm{YO}-\mathrm{fed}$ mice muscle contained more EPA than the AO- and SO-fed mice $(\mathrm{P}<0.05)$; muscle EPA of YO-fed mice was greater than that of SO-fed mice $(\mathrm{P}<0.05)$. Muscle DHA percent (Figure 3b), at week 2, was greater in FO-fed mice than muscle of $\mathrm{YO}$ - and SO-fed mice $(\mathrm{P}<0.05)$, and muscle of AO-fed mice contained more DHA than muscle of SO-fed mice $(\mathrm{P}<0.05)$. At week 4, FO-, AO, and AO+YO-fed mice muscle DHA was greater than that of muscle from YO- and SO-fed mice $(\mathrm{P}<0.05)$.

Adipose EPA percent (Figure 4a) at week 2 was greater in adipose tissue of FO-fed mice than in adipose tissue of SO-, YO-, and AO-fed mice. Adipose EPA was greater in YO- and AO+YO-fed mice than in SO- and AO-fed mice $(\mathrm{P}<0.05)$ at week 2. At week 4, FO-fed mice had the greatest percent of adipose EPA; YO- and AO+YO-fed mice had a greater EPA percent than SO- and AO-fed mice $(\mathrm{P}<0.05)$. Adipose DHA percent (Figure 4b) at week 2 was significantly greater in FO-fed mice compared to SO-, AO-, and YO-fed mice ; AO+YO-fed mice had a greater muscle DHA percent than SO- and YO-fed mice $(\mathrm{P}<0.05)$. At week 4, FO-fed mice adipose contained more DHA than all other treatments, while AO+YO fed mice adipose had a greater percent than SO-fed mice $(\mathrm{P}<0.05)$.

\section{Fatty acid composition of fecal samples}

Diet or week did not affect $(\mathrm{P}>0.05)$ percent of total lipid excreted (data not shown). Percent of EPA in fecal lipid (Figure 5a) was highest in FO-fed mice at week $1(\mathrm{P}<0.05)$, and feces of $\mathrm{AO}+\mathrm{YO}-$ and YO-fed mice contained more EPA $(\mathrm{P}<0.05)$ than SO- and AO-fed mice. AO-fed mice feces contained more EPA than SO-fed mice $(\mathrm{P}<0.05)$. At weeks 2-4, AO+YO-, YO-, and FO-fed mice generated greater fecal EPA than SO- and AO-fed mice $(\mathrm{P}<0.05)$. FO- and YO-fed mice feces contained more EPA at week 
1 than at weeks 2-4 $(\mathrm{P}<0.05)$; AO+YO-fed mice generated greater amounts from week 1 than week 2 $(\mathrm{P}<0.05)$. The AO-fed mice generated more fecal EPA at week 1 than at weeks 2 and $4(\mathrm{P}<0.05)$.

Fecal DHA (Figure 5b) was greatest for AO+YO-fed mice at weeks 1-3 $(\mathrm{P}<0.05)$. FO- and AOfed mice produced more fecal DHA at week 1 than did SO- and YO-fed mice $(\mathrm{P}<0.05)$. Fecal DHA was similar for FO- and AO-fed mice. At weeks 2 and 3, AO-fed mice had greater fecal DHA content than FO-fed mice $(\mathrm{P}<0.05)$. At week $4 \mathrm{AO}-$ and $\mathrm{AO}+\mathrm{YO}-$ fed mice generated the most fecal DHA $(\mathrm{P}<0.05)$; FO-fed mice fecal DHA was greater than that of the SO and YO-fed mice $(\mathrm{P}<0.05)$. Percent DHA in fecal lipid for $\mathrm{AO}+\mathrm{YO}-\mathrm{fed}$ mice was greater at weeks 1-3 than at week $4(\mathrm{P}<0.05)$.

\section{Thin Layer Chromatography}

Oils were separated by TLC with triglyceride, phospholipid, free fatty acid, cholesteryl ester, and cholesterol standards. All of the oils had visible bands in line with the triglyceride standard and no other bands were visible (Figure 6).

\section{Positional analysis}

An equal distribution of fatty acids in a TG would give $66 \%$ at the sn- $1 / 3$ positions and $33 \%$ at the sn-2 position. FO exhibited an unequal fatty acid distribution of DHA with $62 \%$ at the sn-2 position and $46 \%$ EPA at the sn-2 position (Table 4). YO and AO had relatively equal distribution of EPA (32\%) and DHA (40\%) respectively.

\section{Discussion:}

Previous studies from our lab showed, when comparing AO and FO, that FO caused a decrease in body fat and greater DHA incorporation compared to AO, with no changes in BW or feed intake [198]. AO is required to be fed at double the amount of dietary DHA in order to get incorporation similar to FOfed mice [199]. We conducted this experiment to better understand the effects of EPA in FO and to explain differences in tissue incorporation between $\mathrm{AO}$ and $\mathrm{FO}$ in mouse diets. 
Similar to those previous results [198] we detected effects of diet on final body weight or average daily feed intake. The trend for a lower body fat index in FO- and YO-fed mice versus AO+YO-fed mice was unexpected; in fact, we expected to see differences between control and experimental diets and we did not. We have no explanation as to why this difference occurred. Although there was no difference in brain weight, relative brain weight when compared to body weight was greater for YO-fed mice at week 2. We attribute the difference in relative brain weight to numerical differences with body weight and brain weight. DHA is normally associated with brain development [204], so any differences we did see we thought would have been with the $\mathrm{AO}$ or FO diets. FO-fed mice had greater relative liver weights which often relates to liver lipid; nonetheless, no differences in total lipid percent or TG content were observed [205].

We measured fatty acid composition of adipose and muscle tissue to identify where EPA and DHA are incorporated. We observed very little EPA and DHA in adipose and muscle tissue for SO-fed mice. With incorporation of EPA and DHA into adipose and muscle tissue, it was expected that SO-fed mice would have the lowest amount because there was minimal in the diet and conversion from ALA to EPA is poor. Moreover subsequent conversion of EPA to DHA is not substantial [194] and there was not a lot of ALA in the diet, about $8 \%$ of lipid. There was more EPA and DHA in muscle than adipose tissue in SO-fed mice since there was little in the diet to be stored in the adipose tissue while conversion from ALA would be needed for incorporation into muscle. EPA on the other hand shows some conversion to DHA, as well as DHA retro conversion back to EPA [194]. These interconversions explain why we see moderate amounts of DHA in the tissues from the YO-fed mice and moderate EPA from the AO-fed mice. We detected the greatest amount of EPA and DHA in adipose and muscle tissues for the FO treatment. Treatment could be due to differences in digestibility.

Because treatment affected tissue DHA and we measured fatty acid composition of fecal samples as a potential reason for these differences. We detected greater amounts of DHA in fecal lipid for AO treatments compared to the FO treatments; AO+YO-fed mice yielded the greatest fecal DHA from weeks 
1-3. Greater excretion of DHA from the feces of AO-fed mice could explain why there is less incorporation of DHA into their tissues (i.e. less was absorbed). We thus performed a correlation analysis, and observed a positive correlation between fecal DHA (average of 4 weeks) and both adipose tissue DHA $(r=0.46, \mathrm{P}=0.0048)$ and muscle DHA $(\mathrm{r}=0.48, \mathrm{P}=0.0034)$ indicating that mice that were fed DHA (FO, AO, and AO+YO) had greater fecal and tissue DHA. However, when the correlation analysis was performed only with mice receiving DHA in the diet no significant correlations were observed (fecal-adipose $\mathrm{r}=0.011, \mathrm{P}=0.96$; fecal-muscle $\mathrm{r}=0.41, \mathrm{P}=0.065$ ). The AO+YO-fed mice, which had greater fecal DHA and equal tissue DHA as the AO-fed mice may be affecting this analysis. Alternatively, the smaller sample size $(n=21)$ of mice fed DHA and used for the fecal analysis could be impacting our ability to detect a significant correlation. We did not detect treatment differences in EPA between FO and YO groups; however, time affected fecal losses, and the greatest losses in EPA occurred at week 1 . This observation might be due to adaptation to the different oils by the mice to increase absorption of EPA. Similar to DHA, fecal EPA (average of the 4 weeks) was positively correlated with both adipose $(r=0.71, P=0.0001)$ and muscle $(r=0.54, P=0.0009)$ EPA when all mice $(n=35)$ were included. When only mice fed EPA (FO, YO, and AO+YO) were included no significant correlations were detected (fecal-adipose $\mathrm{r}=0.23, \mathrm{P}=0.31$; fecal-muscle $\mathrm{r}=0.17, \mathrm{P}=0.47$ ).

Since different lipid classes have different absorption mechanisms [206]; we tested the composition of the oils using TLC to determine if there are composition differences that could explain the differences in fecal excretion. These data revealed that all treatment oils were primarily composed of TGs, consistent with the manufacturers' labels.

Since there were no differences in lipid classes for the oils, we tested the positional distribution of fatty acids on the TGs. FO had an unequal distribution of EPA and DHA, with 62\% of its DHA and $46 \%$ of its EPA at the sn-2 position. We detected $32 \%$ of EPA at the sn-2 in the YO and $40 \%$ DHA at sn-2 in the AO. This finding is close to equal distribution, where you would expect $33 \%$ sn- 2 and $66 \%$ sn- $1 / 3$. Wang et al. [207] did a similar digestion of menhaden oil using porcine pancreas lipase, and they saw an 
enrichment of DHA at the sn-2 position. They also showed enrichment of EPA for menhaden oil, a larger difference then we determined. Enrichment of DHA at the sn-2 position of FO could explain differences in absorption as suggested by fecal DHA losses. We do not see diet differences in EPA absorption, which corresponds to the lipase digestion showing EPA was more equally distributed on the triglycerides of the oils than DHA. In a study by Christensen et al. [4] EPA and DHA were more readily absorbed when at the sn-2 in the first 5 hours of feeding; however, no differences were in absorption were observed after 24 hours. While we did see differences in absorption of DHA, these differences may be due to having mice on a moderately high fat diet, where diet composition could possibly interfere with complete digestion and absorption of dietary lipids.

Yang et al. [208] showed TG hydrolysis with pancreatic lipase was slower when hydrolyzing TG with DHA and EPA. Also, they showed an even greater increase in hydrolysis time for TGs having more than 1 PUFA attached. With most of the DHA in FO at the sn-2 position, TG hydrolysis is faster than at the sn- $1 / 3$ position [208]. The DHA in AO is mostly at the sn- $1 / 3$ position, and since the DHA in this oil is concentrated to a greater extent than in FO, some of its TGs will have multiple DHA esters that will further slow its hydrolysis. This effect may explain why we see differences in absorption while others have not used different sources of lipids [3]. Studies comparing positional oils of sn-2 and sn-1/3 DHA enriched TGs report the same pattern where a greater accumulation of DHA occurred in lymph from sources primarily at the sn-2 position, compared to primarily at the sn-1/3 position, in the first hours after ingestion, however no differences were detected after 24 hours [204]. Valenzuela et al. [209] showed that supplementation with DHA, in the form of a 2-MG, resulted in greater tissue accumulation than the same amount of DHA administered from algae oil, which coincides with our FO model that has high enrichment of DHA at the sn-2 position. Greater absorption of DHA by the FO-fed mice compared to the AO-fed mice is primarily due to the differences in DHA enrichment at the sn-2 position.

Experimentally Christensen et al. [4] showed feeding rats FO versus seal oil, which has 1/3 enrichment for EPA/DHA, TGs in the chylomicrons mirrored dietary TG content. This similarity is 
primarily due to TG re-esterifying through the 2-MG pathway once they are absorbed [48], so the fatty acids at the sn-2 position in dietary TGs stay at the sn- 2 position once re-esterified. However, this does not support our data in terms of the greater accretion of EPA from FO because we did not see an enrichment of EPA at the sn-2 position for FO. One possible explanation for the differences in EPA incorporation could be differing effects of LPL from the different sources. LPL is regulated by some of the same genes that EPA and DHA affect, mainly peroxisome proliferator-activated receptor $\gamma$ (PPAR) and liver $\mathrm{x}$ receptor (LXR); these transcription factors can activate LPL transcription. Khan et al. [122] showed that omega-3 supplementation increased LPL mRNA in adipose tissue, which PPAR $\gamma$ has been shown to regulate. Harris et al. [210] showed, in patients given FO versus olive oil supplements, that FO supplementation increased LPL activity. Park and Harris [193] showed that omega-3 supplementation increased chylomicron clearance rate, as opposed to an olive oil control, and didn't affect chylomicron secretion. However, with an increase in LPL activity, more EPA from FO would be incorporated into the tissues where EPA is preferentially incorporated into phospholipids [211] and possibly used less readily for oxidation. Harris et al. [210] showed that omega-3 supplementation in rats increased LPL hydrolysis of TGs without an increase in LPL protein levels.

Another possibility could be that something else in YO is causing EPA to be used by the small intestine instead of being repackaged into chylomicrons. Consequently, it is not incorporated into the adipose and muscle tissue at a similar degree as FO. It is possible that the different sources of omega-3's affect chylomicron composition in different ways, possibly changing the ratio of apoC-II, a LPL cofactor, and apoC-III, an inhibitor of LPL, in the chylomicrons or by changing the phospholipid to TG ratio in the chylomicrons which would affect tissue incorporation [210]. Albeit, different positional differences for omega-3s have no effect on the size of chylomicrons being secreted [212]. 
In conclusion, DHA from FO seems to be more available as compared to an algae oil source. This difference could be attributed to the enrichment of DHA at the sn-2 position of the TG in FO. FO-fed mice had greater DHA accretion in adipose when compared to AO-fed mice, and greater accretion of EPA in muscle and adipose compared to YO-fed mice. 
Figures and Tables

a.

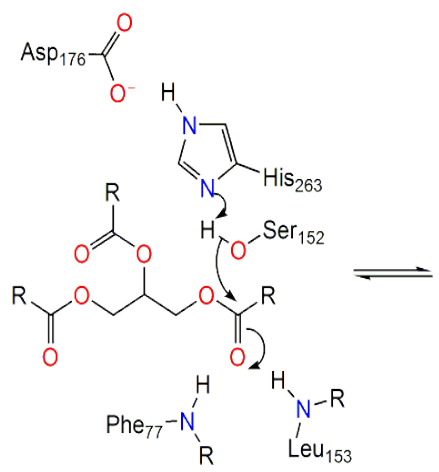

c.
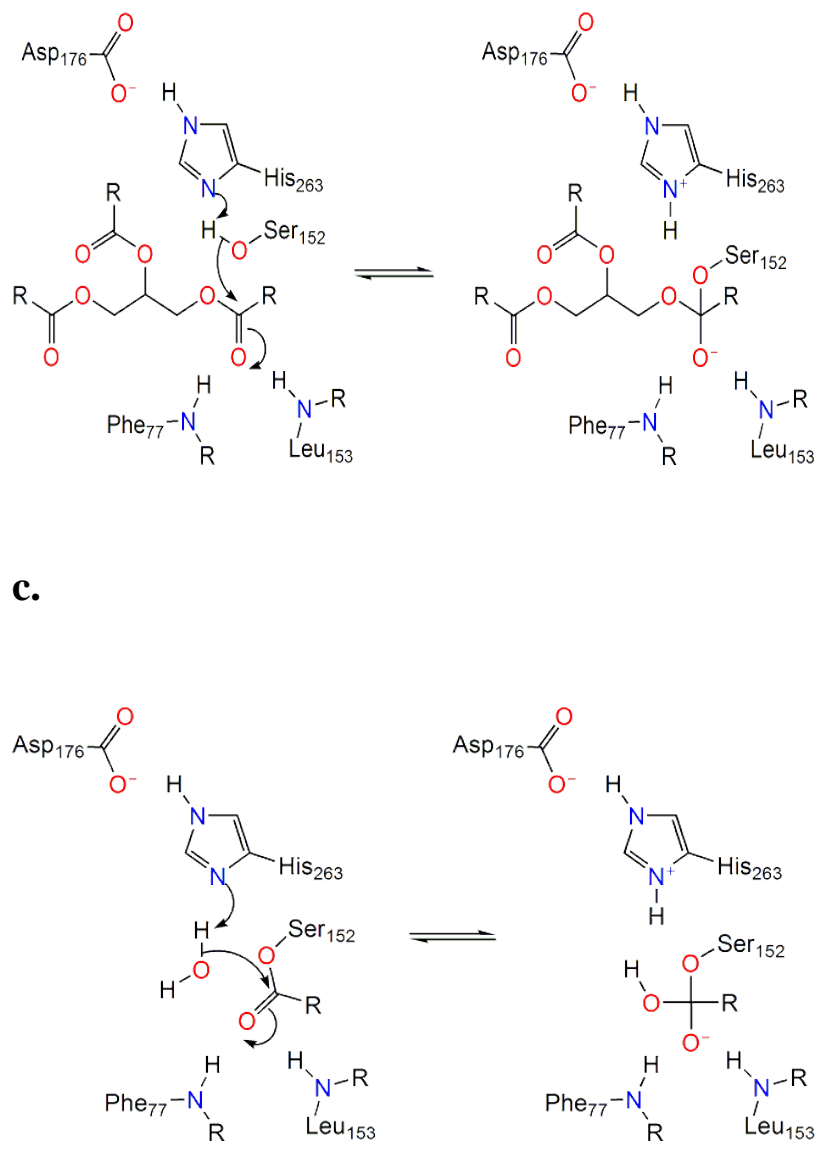

b.
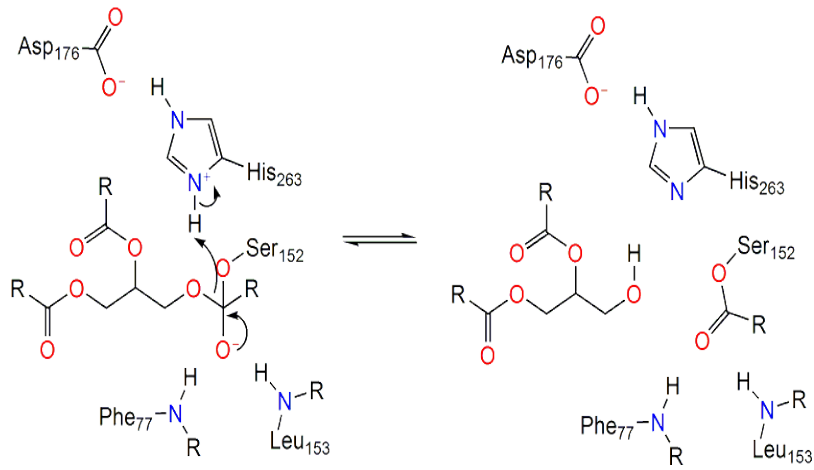

d.

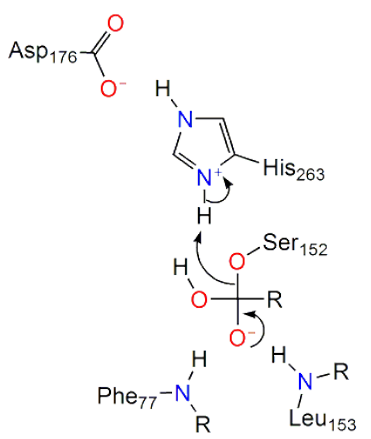

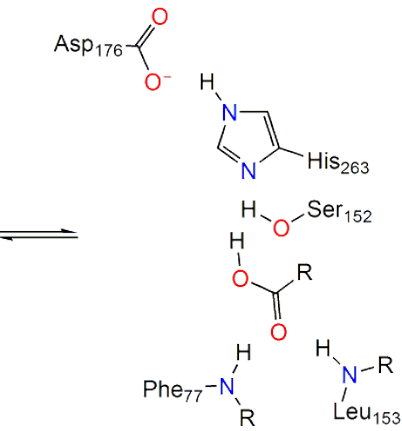

Figure 1. Reaction of pancreatic lipase [213]: Diagram of the hydrolysis of TG by lipase. The aspartic acid forms a hydrogen bond with the serine causing it to act as a nucleophile and attack the carbonyl group of the TG (a). The tetrahedral intermediate is stabilized by the oxyanion hole between the leucine and phenylalanine. The carbonyl reforms with glycerol acting as a leaving group (b). A water molecule donates a proton to histidine to create a hydroxl anion which attacks the lipid (c) forming another tetrahedral intermediate again stabilized in the oxyanion hole. The carbonyl is reformed (d) and the fatty acid diffuses away. 


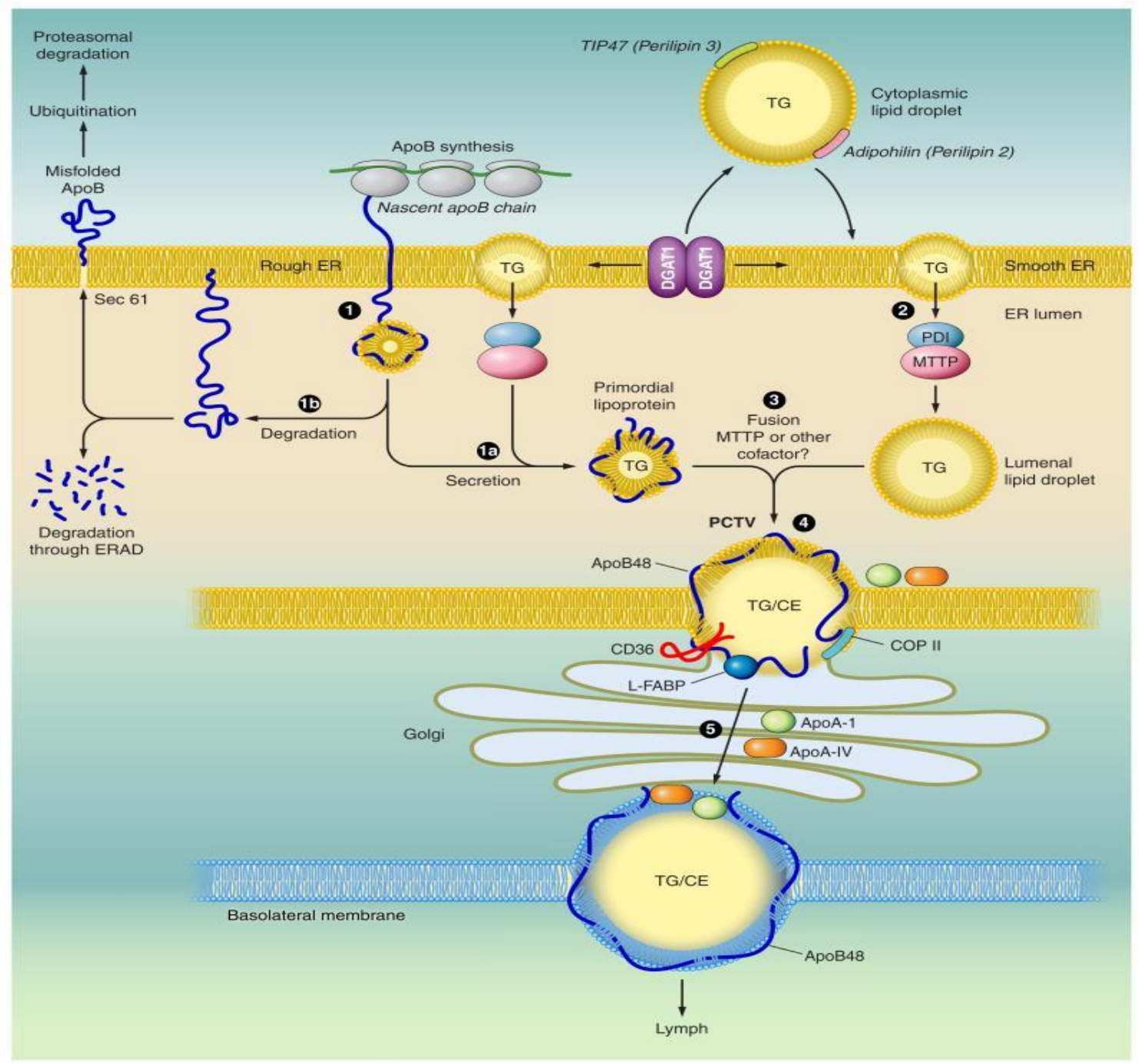

Figure 2. Chylomicron formation [206]: Model of TG repackaging into chylomicron. apoB is translocated into the ER where it interacts with TG (1) and microsomal triacylglycerol transfer protein (MTTP) helps it in correctly folding into apoB48 (1a). When lipid is not present the apoB is degraded (1b). MTTP is also involved in shuttling TGs into the ER lumen (2). The TGs collect and fuse in the ER lumen, aided by MTTP (3). Once the droplet becomes a pre-chylomicron transfer vesicle (PCTV) it interacts with CD36 to help budding, fatty acid binding protein 1(FABP1) for transport, and coatomer II proteins (COPII) for aid in reaching the golgi (4). Once fused with the golgi the pre-chylomicron undergoes more processing with more apolipoproteins added as well as glycosylation of apoB48 (5). The chylomicron is then transported to the basolateral membrane and enters the lymph. 
Table 1 Composition of experimental diets

\begin{tabular}{lccccc}
\hline Ingredient(g/kg) & $\mathbf{S O}^{\mathbf{1}}$ & $\mathbf{F O}^{2}$ & $\mathbf{A O}^{2}$ & $\mathbf{Y O}^{2}$ & $\mathbf{A O + Y O}^{2}$ \\
\hline Isolated Soy Protein & 200 & 200 & 200 & 200 & 200 \\
Cornstarch & 345.42 & 345.42 & 345.42 & 345.42 & 345.42 \\
Dextronized Cornstarch & 132 & 132 & 132 & 132 & 132 \\
Sucrose & 100 & 100 & 100 & 100 & 100 \\
Cellulose & 50 & 50 & 50 & 50 & 50 \\
Soy Oil & 120 & - & 92.7 & 97.79 & 70.49 \\
Fish Oil & - & 120 & - & - & - \\
Algae Oil & - & - & 27.3 & - & 27.3 \\
Yeast Oil & - & - & - & 22.21 & 22.21 \\
AIN-93G Mineral Mix & 35 & 35 & 35 & 35 & 35 \\
AIN-93G Vitamin Mix & 10 & 10 & 10 & 10 & 10 \\
L-Cysteine & 2.54 & 2.54 & 2.54 & 2.54 & 2.54 \\
L-Methionine & 2.54 & 2.54 & 2.54 & 2.54 & 2.54 \\
Choline Bitartrate & 2.5 & 2.5 & 2.5 & 2.5 & 2.5 \\
\hline
\end{tabular}

${ }^{1}$ All numbers presented as $\mathrm{g} / \mathrm{kg}$ of diet. Algae oil obtained from Martek Biosciences and yeast oil obtained from Futurebiotics. All other ingredients were obtained from Dyets Inc.

${ }^{2} \mathrm{SO}=$ Soy Oil-fed mice, $\mathrm{FO}=$ Fish Oil, $\mathrm{AO}=$ Algae Oil, $\mathrm{YO}=$ Yeast Oil, AO+YO=Algae Oil + Yeast Oil. 
Table 2 Fatty acid percent composition of dietary oils

\begin{tabular}{|c|c|c|c|c|}
\hline Fatty Acid ${ }^{1}$ & Fish & Yeast & Algae & Soy \\
\hline $\mathrm{C} 10$ & $\mathrm{ND}^{2}$ & ND & 1.51 & ND \\
\hline $\mathrm{C} 12$ & 0.25 & ND & 7.98 & ND \\
\hline C13 & 0.12 & ND & ND & ND \\
\hline $\mathrm{C} 14$ & 15.15 & 0.13 & 19.38 & 0.06 \\
\hline C14:1 & 0.11 & ND & 0.49 & ND \\
\hline C15 & 1.41 & 0.16 & ND & 0.01 \\
\hline C15:1 & 0.03 & ND & ND & ND \\
\hline C16 & 25.76 & 3.63 & 12.92 & 10.00 \\
\hline C16:1 & 16.69 & 0.55 & 3.51 & 0.08 \\
\hline C17 & 0.80 & 0.36 & 0.02 & 0.09 \\
\hline C17:1 & 0.04 & 0.02 & 0.02 & 0.12 \\
\hline C18 & 3.34 & 2.39 & 0.80 & 3.30 \\
\hline C18:1n9t & 0.16 & 0.21 & ND & 0.05 \\
\hline C18:1n9c & 8.39 & 5.19 & 25.12 & 19.75 \\
\hline $\mathrm{C} 18: 2 \mathrm{n} 6 \mathrm{t}$ & 0.02 & 0.15 & 0.07 & 0.00 \\
\hline C18:2n6c & 1.66 & 19.98 & 1.59 & 57.06 \\
\hline C20 & 0.16 & 0.02 & 0.06 & 0.22 \\
\hline C18:3n6 & 0.42 & 0.33 & ND & 0.23 \\
\hline C20:1 & 0.58 & 0.06 & 0.06 & 0.39 \\
\hline C18:3n3 & 1.85 & 1.35 & 0.04 & 8.16 \\
\hline C21 & 0.04 & 0.76 & ND & ND \\
\hline C20:2 & 3.94 & 1.90 & 0.09 & 0.15 \\
\hline $\mathrm{C} 22$ & 0.05 & 0.04 & 0.09 & 0.22 \\
\hline C20:3n6 & 0.18 & 2.92 & ND & 0.03 \\
\hline C22:1n9 & 0.06 & 0.04 & ND & 0.01 \\
\hline C20:3n 3 & 0.18 & 0.22 & ND & ND \\
\hline $\mathrm{C} 23$ & 0.75 & 0.73 & ND & 0.01 \\
\hline $\mathrm{C} 22: 2$ & 1.23 & 1.05 & ND & ND \\
\hline C24 & 0.04 & 0.79 & ND & 0.04 \\
\hline C20:5n3 & 10.54 & 56.81 & 0.47 & 0.01 \\
\hline C24:1 & 0.18 & 0.14 & ND & 0.01 \\
\hline C22:6n3 & 5.86 & 0.08 & 25.79 & ND \\
\hline
\end{tabular}

${ }^{\mathrm{I}}$ Percent of fatty acids in the oils used to make the dietary treatments, based on fatty acids identified compared to the standard used.

${ }^{2}$ Not detected 
Table 3 Body composition data of mice

\begin{tabular}{|c|c|c|c|c|c|c|c|c|}
\hline & Week & SO $^{1}$ & FO $^{1}$ & $\mathrm{AO}^{1}$ & YO $^{1}$ & $\mathrm{AO}+\mathrm{YO}^{1}$ & P Value & SEM \\
\hline \multicolumn{9}{|l|}{ Final Body } \\
\hline \multirow[t]{2}{*}{ Weight $(\mathrm{g})^{2}$} & 2 & 37.20 & 37.62 & 37.73 & 35.79 & 37.98 & 0.109 & 0.61 \\
\hline & 4 & 39.86 & 40.08 & 39.68 & 40.15 & 40.92 & 0.928 & 1.02 \\
\hline \multicolumn{9}{|l|}{ Average Daily } \\
\hline \multicolumn{9}{|l|}{ Feed Intake } \\
\hline$(g / d)^{2}$ & 2 & 6.25 & 6.05 & 5.17 & 5.80 & $\begin{array}{l}5.43 \\
5.10\end{array}$ & 0.065 & 0.28 \\
\hline \multicolumn{9}{|l|}{ Relative Brain } \\
\hline \multirow[t]{2}{*}{$\begin{array}{l}\text { Weight (\% of } \\
\text { body weight) }\end{array}$} & 2 & $\mathbf{a b}_{1.29}$ & ${ }^{a} 1.29$ & ${ }^{\mathrm{a}} 1.26$ & $\mathbf{b}_{1.37}$ & ${ }^{\mathrm{a}} 1.24$ & 0.016 & 0.03 \\
\hline & 4 & 1.14 & 1.13 & 1.18 & 1.12 & 1.11 & 0.863 & 0.05 \\
\hline \multicolumn{9}{|l|}{ Relative Liver } \\
\hline \multirow[t]{2}{*}{$\begin{array}{l}\text { Weight (\% of } \\
\text { body weight })^{2}\end{array}$} & 2 & $c_{4.50}$ & ${ }^{a} 5.16$ & $\mathbf{b c}_{4.71}$ & $\mathbf{a b}_{4.96}$ & $\mathbf{a b c}_{4.79}$ & 0.015 & 0.13 \\
\hline & 4 & $\mathbf{b}_{4.54}$ & $\mathrm{a}_{5.29}$ & $\mathbf{b}_{4.69}$ & $\mathbf{b}_{4.56}$ & $\mathbf{b}_{4.62}$ & 0.003 & 0.14 \\
\hline \multicolumn{9}{|l|}{ Relative Heart } \\
\hline \multirow[t]{2}{*}{$\begin{array}{l}\text { Weight (\% of } \\
\text { body weight) }{ }^{2}\end{array}$} & 2 & 0.50 & 0.49 & 0.46 & 0.45 & 0.45 & 0.105 & 0.02 \\
\hline & 4 & 0.48 & 0.49 & 0.50 & 0.47 & 0.52 & 0.455 & 0.02 \\
\hline \multirow[t]{2}{*}{$\begin{array}{l}\text { Body Fat } \\
\text { Index }^{2}\end{array}$} & 2 & $\mathbf{a b}_{2.94}$ & ${ }^{a} 2.54$ & $\mathbf{a b}_{2.94}$ & $\mathrm{a}_{2.52}$ & $\mathbf{b}_{3.18}$ & 0.098 & 0.20 \\
\hline & 4 & 4.68 & 3.39 & 3.93 & 3.63 & 4.07 & 0.316 & 0.44 \\
\hline
\end{tabular}

${ }^{1} \mathrm{SO}=$ Soy Oil-fed mice, FO=Fish Oil-fed mice, $\mathrm{AO}=$ Algae Oil-fed mice, $\mathrm{YO}=$ Yeast Oil-fed mice, $\mathrm{AO}+\mathrm{YO}=\mathrm{Algae}$ Oil + Yeast Oil-fed mice.

${ }^{2}$ Final body weight in grams. Average daily feed intake throughout experiment in grams. Relative brain, liver, and heart measured by weight of (organ weight/final body weight)x 100, represented in g/g body weight. Body fat index calculated as reteroperitoneal + epididymal fat pad weights/final body weight $\times 100 .{ }^{\mathrm{abc}}$ indicate significant differences between diets within week. 
a.

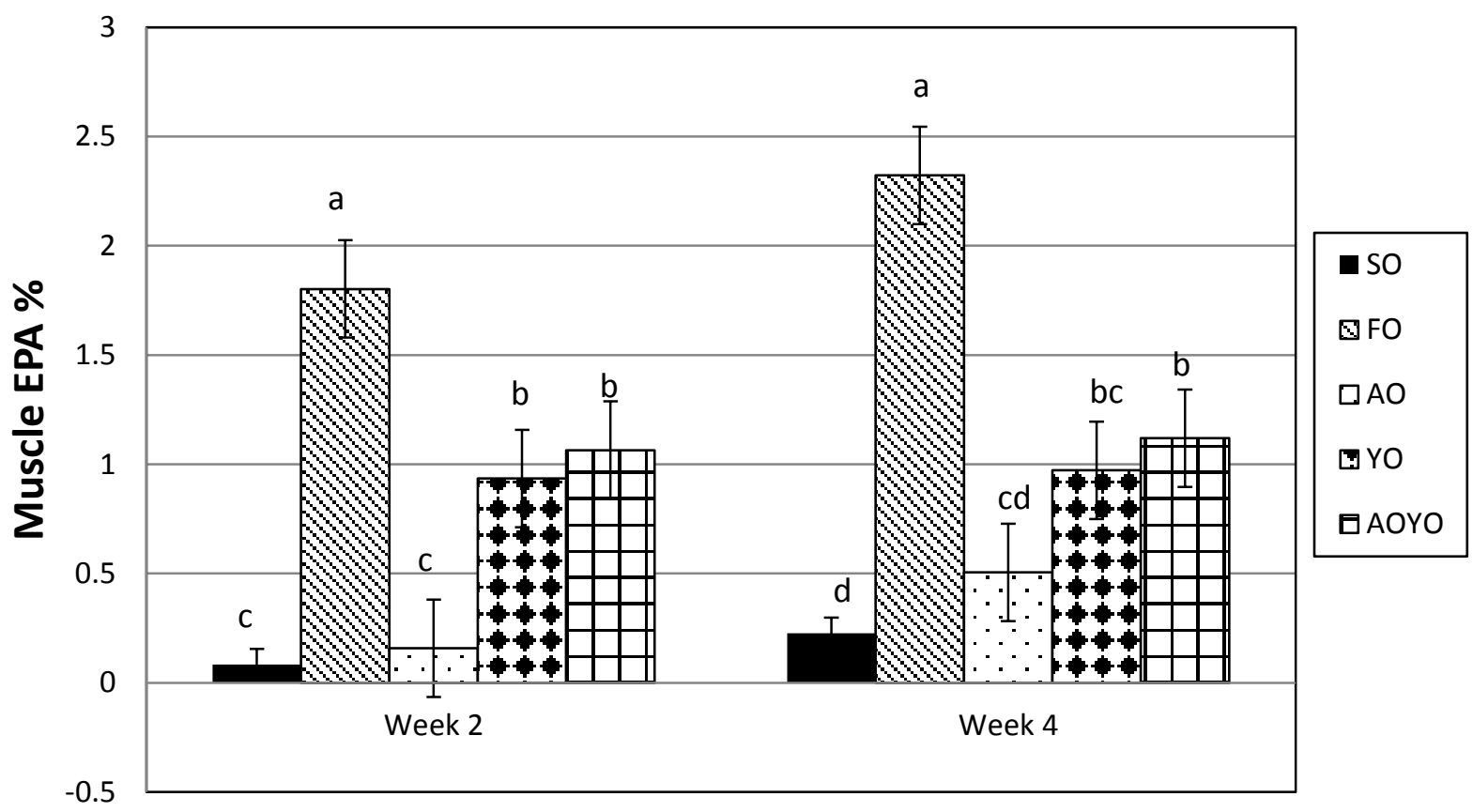

b.

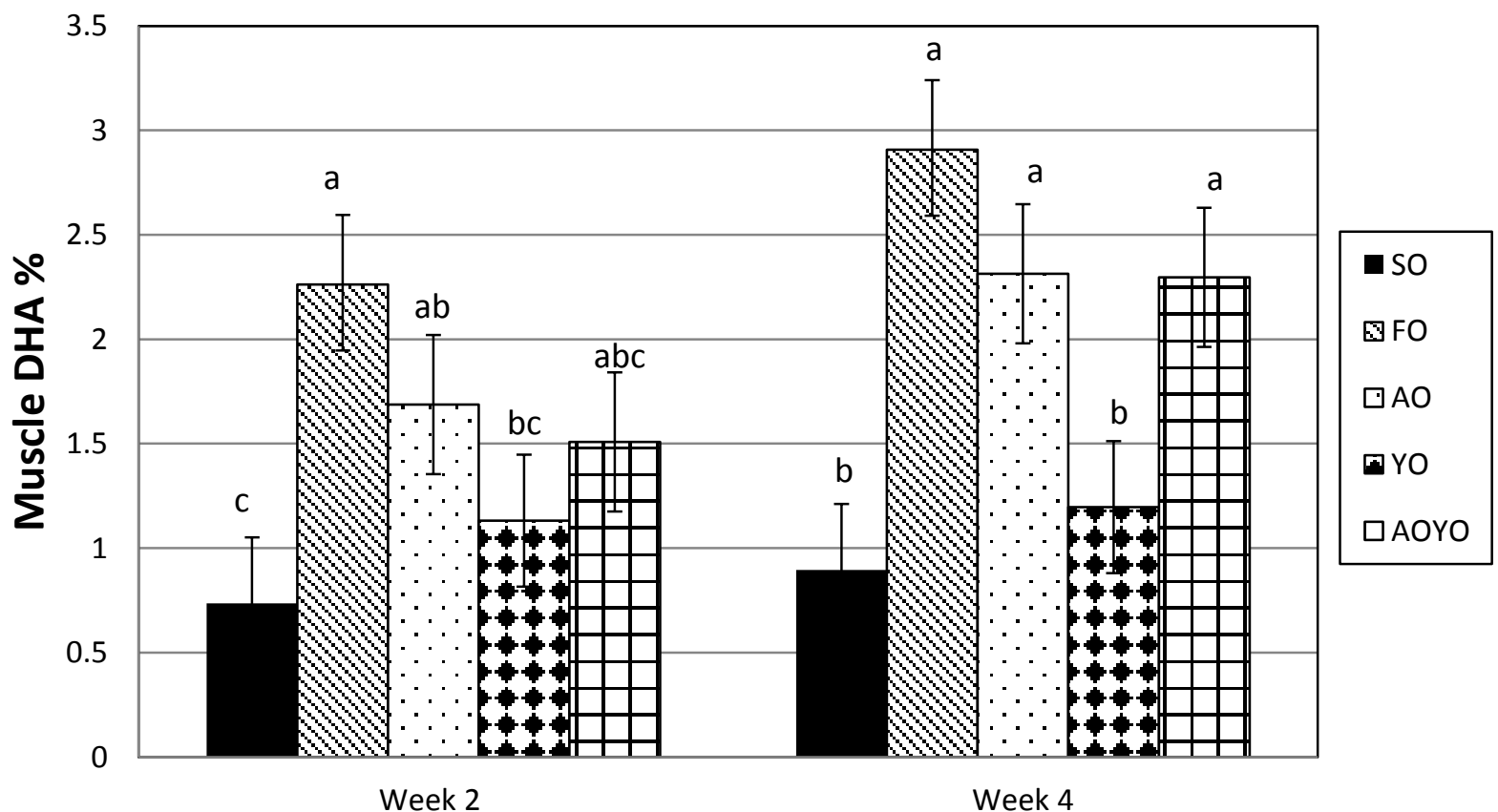

Figure 3. Effect of dietary treatment on muscle fatty acids: Muscle EPA (a) and muscle DHA (b) fatty acid percent of mice $(n=100)$ from week 2 and week 4 . Percent calculated as fatty acid peak area/total identified fatty acid peak area $x 100$. Data expressed as means \pm SEM. Different letters indicate significant differences between diets within week $(\mathrm{P}<0.05)$. 
a.

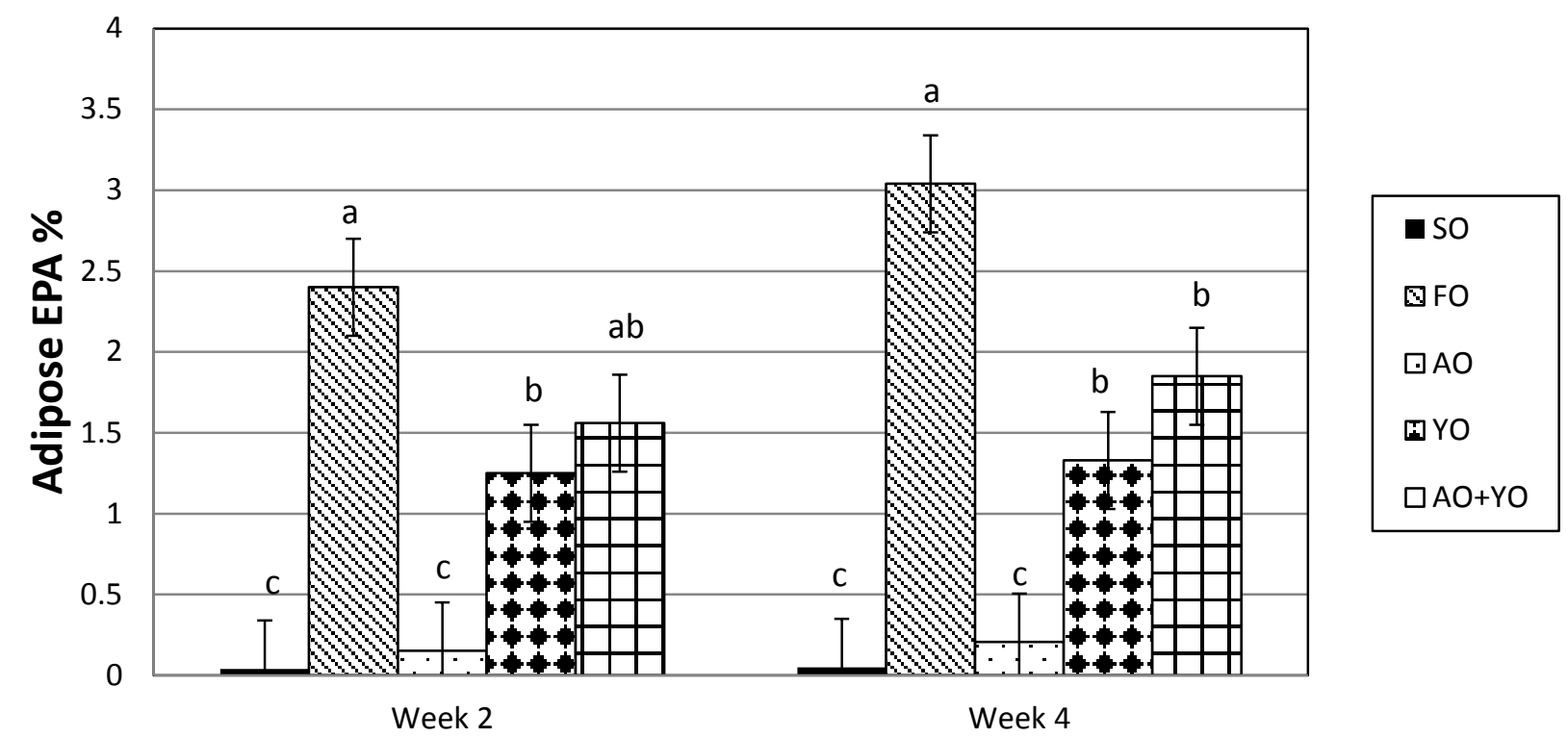

b.

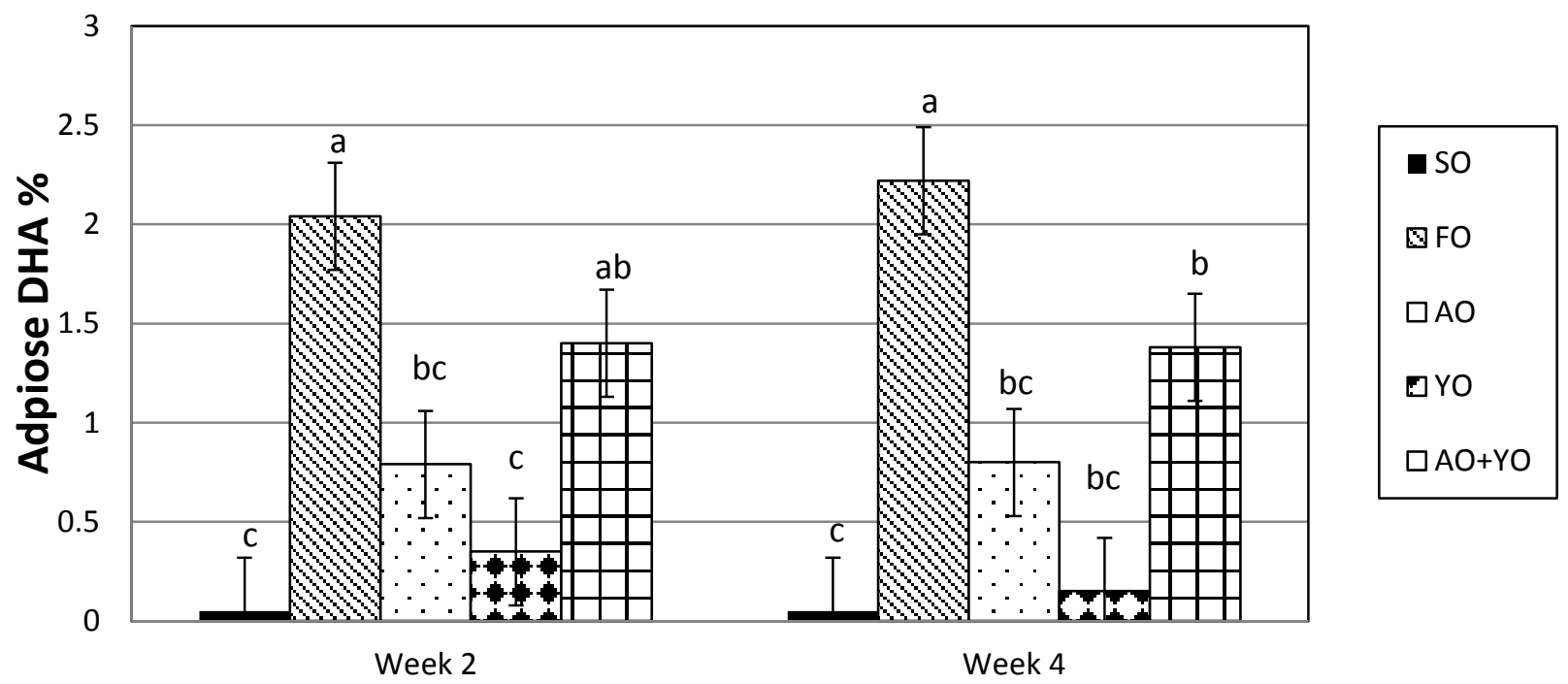

Figure 4. Effect of dietary treatment on adipose tissue fatty acids: Adipose EPA (a) and DHA (b) fatty acid percent of mice $(n=100)$ from week 2 and week 4 . Percent calculated as fatty acid peak area/total identified fatty acid peak area $x 100$. Data expressed as means \pm SEM. Different letters indicate significant differences between diets within week $(\mathrm{P}<0.05)$. 
a.

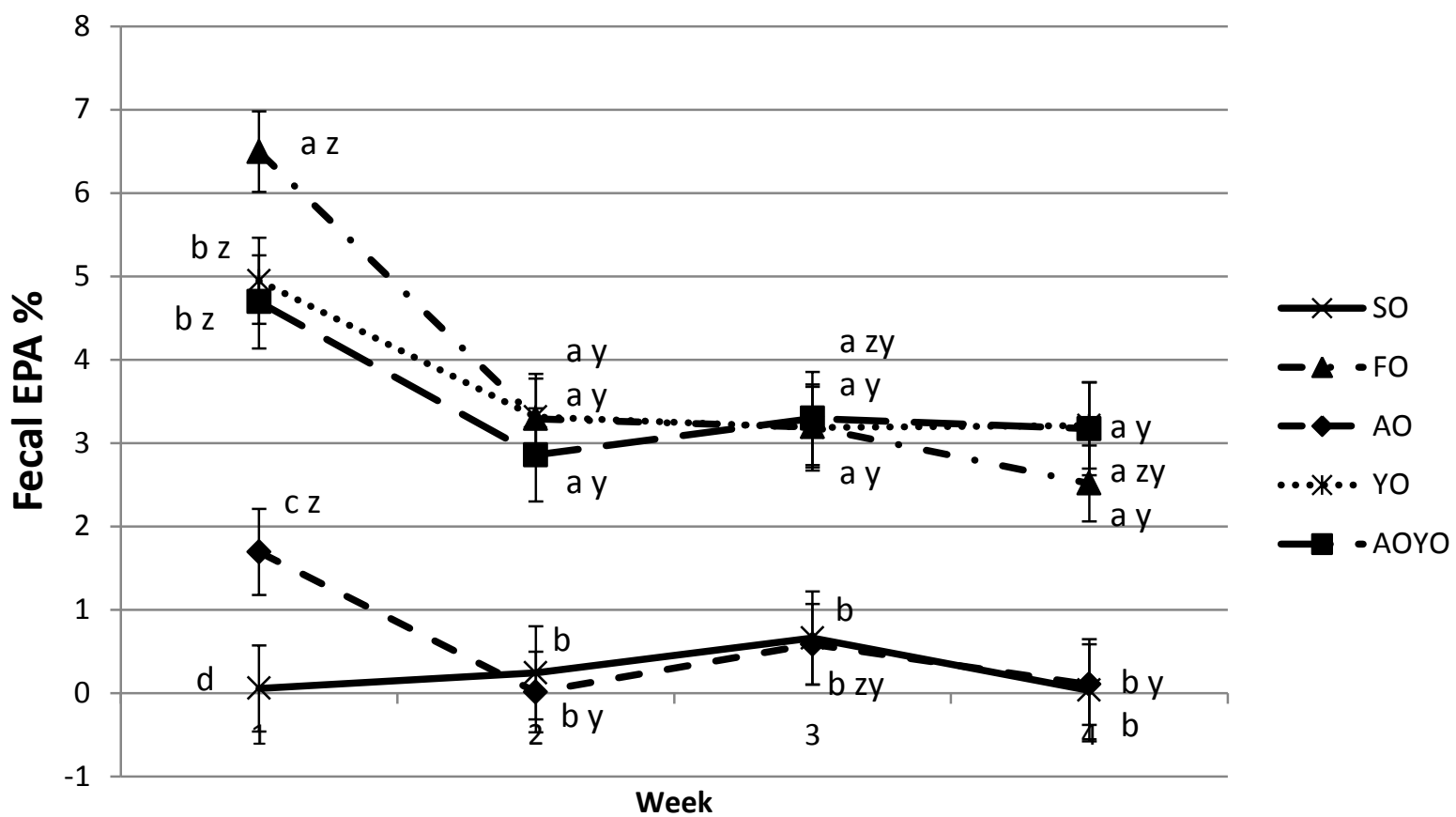

b.

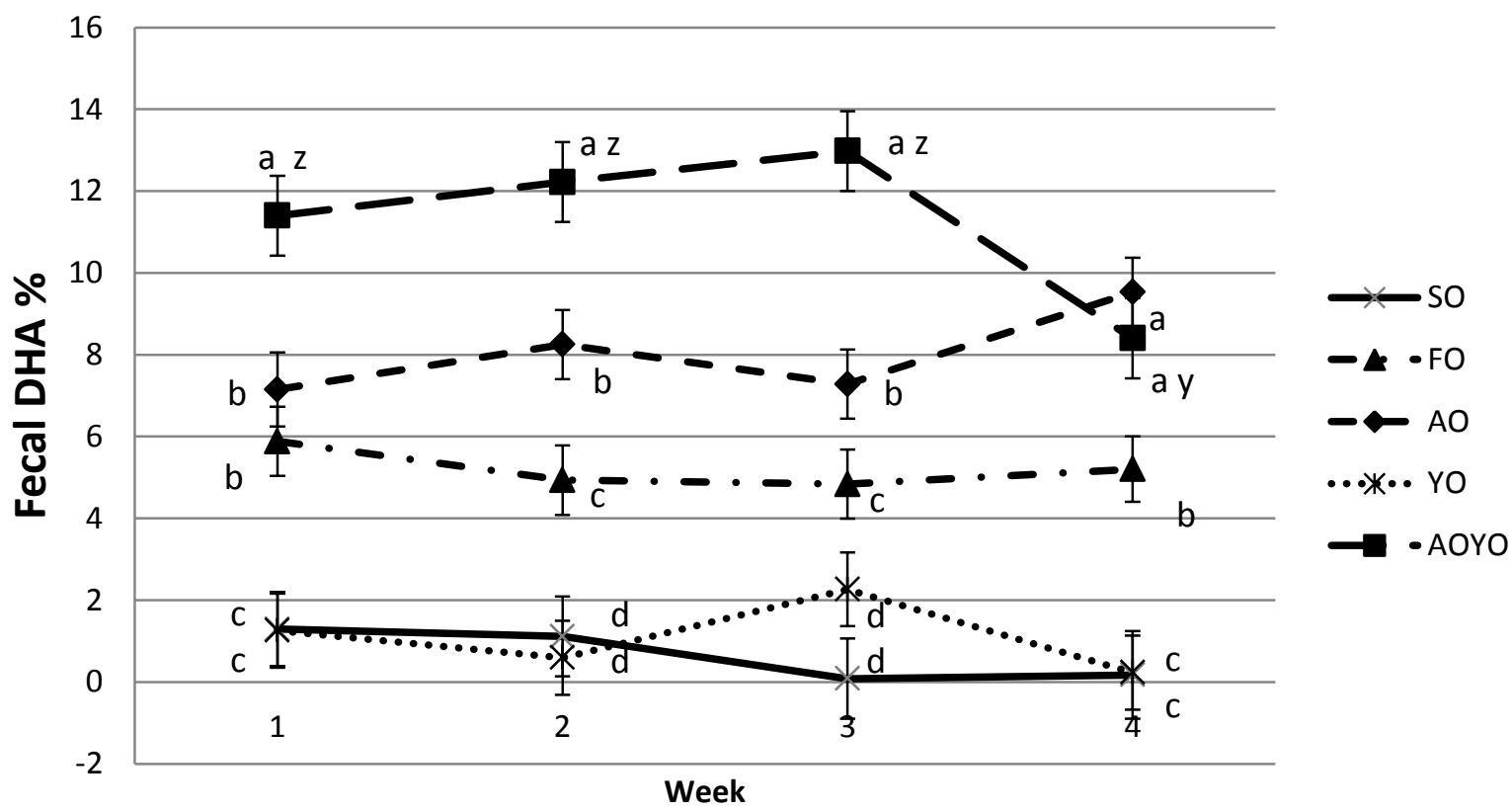

Figure 5. Effect of dietary treatment on fecal fatty acid composition: Fecal EPA (a) and DHA (b) percent of total fecal fatty acids, calculated as fatty acid peak area/total fatty acids identified peak area. Data expressed as means \pm SEM. ${ }^{\text {abcd }}$ indicate significant differences between diets within week $(\mathrm{P}<.05)$, ${ }^{\mathrm{yz}}$ represent differences between week within diet $(\mathrm{P}<0.05)$. 


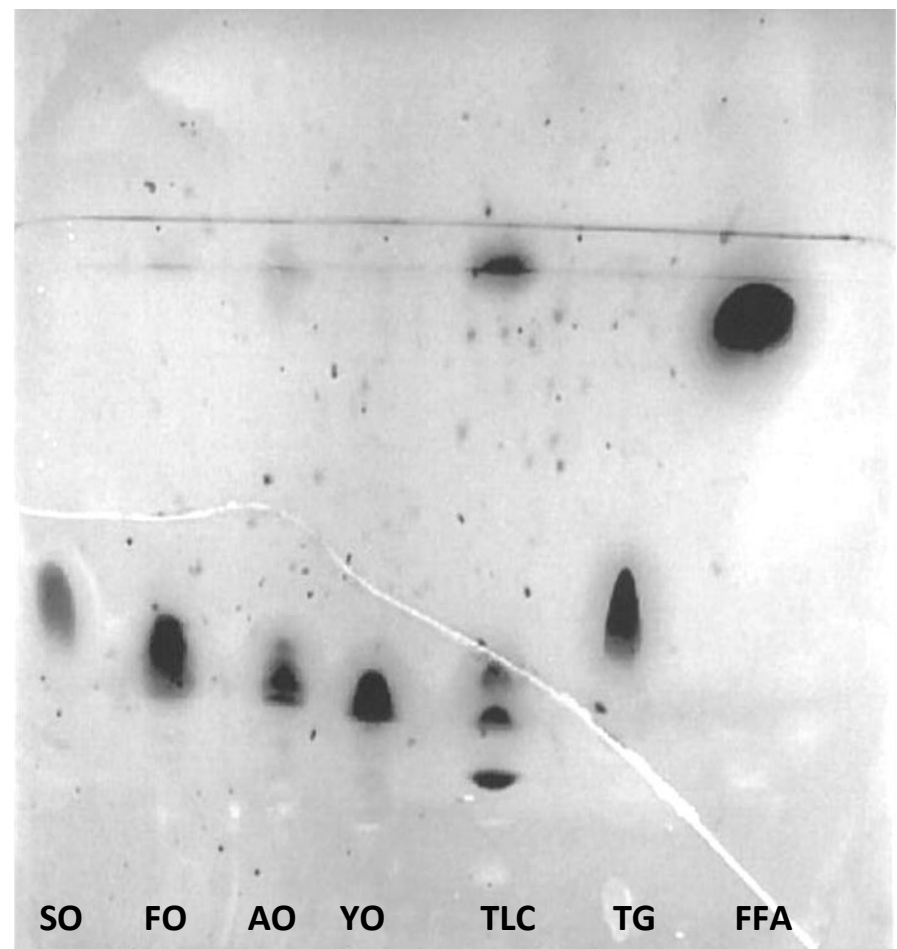

Figure 6. Thin Layer Chromatography of Oils: Picture of thin layer chromatography plate of the oils. Oils were spotted and assayed in hexane:diethyl ether:acetic acid solution and charred for visibility. From left to right the oils are soy oil, fish oil, algae oil, and yeast oil. The TLC standard run contains, in order from top to bottom, free fatty acid, triglyceride, cholesteryl ester, free cholesterol, and phospholipid which is not visible. Next is triglyceride standard and then free fatty acid standard. The dietary oils appear to only have bands where the triglyceride should be with no other visible bands. 
Table 4. Positional analysis of fatty acids on the triglycerides of the oils

\begin{tabular}{lrrr}
\hline & Total\% & $\begin{array}{r}\mathbf{s n 1 / 3 \%} \text { of } \\
\text { total }\end{array}$ & $\begin{array}{r}\text { sn2\% of } \\
\text { total }\end{array}$ \\
\hline SO EPA & 0 & 0 & 0 \\
FO EPA & 15.14 & 53.96 & 46.04 \\
AO EPA & 0.03 & 100 & 0 \\
YO EPA & 60.99 & 68.32 & 31.64 \\
SO DHA & 0 & 0 & 0 \\
FO DHA & 14.04 & 38.03 & 61.97 \\
AO DHA & 43.16 & 59.78 & 40.22 \\
YO DHA & 0 & 0 & 0 \\
\hline
\end{tabular}

Dietary oils used were digested using a lipase and separated on thin layer chromatography. The monoglyceride portion was extracted and analyzed for fatty acids to measure sn-2 position. Data are expressed as percent of fatty acid in total fatty acids of oil, percent of the fatty in sn-1/3 position, and percent of the fatty acid in sn-2 position. 


\section{References}

[1] A. Cameron, Shaw J and Zimmet P, "The metabolic syndrom: Prevalence in worldwide populations.," Endocrinology and Metabolism Clinics of North America, vol. 33, pp. 351-375, 2004.

[2] A. Bernstein , E. Ding, W. Willett and E. Rimm, "Journal of Nutrition," vol. 142, pp. 99-104, 2012.

[3] H. Yoshida, J. Kumamaru, M. Mawatari, I. Ikeda, K. Imaizumi, H. Tsuji and A. Seto, "Lymphatic absorption of seal and fish oils and their effect on lipid metabolism and eicosanoid production in rats," Bioscience, Biotechnology, and Biochemistry, vol. 60, no. 8, pp. 1293-1298, 1996.

[4] M. Christensen and C. Hoy, "Effects of dietary triacylglycerol structure on triacylglycerols of resultant chylomicrons from fish oil and seal oil fed rats," Lipids, vol. 31, no. 3, pp. 341-344, 1996.

[5] F. Carriere, J. Barrowman, R. Verger and R. Laugier, "Secretion and contribution to lipolysis of gastric and pancreatic lipases during a test meal in humans.," Gastroenterology, vol. 105, pp. 876888, 1993.

[6] H. Mu and T. Porsgaard, "The metabolism of structured triacylglycerols," Progress in lipid research, vol. 44, pp. 430-448, 2005.

[7] J. Williams, "Intracellular signaling mechanisms activated by cholecystokinin-regulating synthesis and secretionof digestive enzymes in pancreatic acinar cells," Annual Review of Physiology, vol. 63, pp. 77-97, 2001.

[8] B. Entressangles and P. Desnuelle, "Action of pancreatic lipase on aggregated glyceride molecules in an isotropic system," Biochimica et Biophysica Acta, vol. 159, no. 2, pp. 285-295, 1968.

[9] G. Benzonana and P. Desnuelle, "Action of some effectors on the hydrolysis of long-chain triglycerides by pancreatic lipase," biochimica et Biophysica, vol. 164, no. 1, pp. 47-58, 1968.

[10] H. Porter, D. Saunders, G. Tytgat, O. Brunser, C. Rubin, L. Muglia and M. Lowe, "Fat absorption in bile fistula man. A morphological and biochemical study," Gastroenterology, vol. 60, pp. 10081019, 1971.

[11] B. Borgstrom and C. Erlanson, "Pancreatic lipase and colipase. Interaction and effects of bile salts and other detergents," European Journal of Biochemistry, vol. 37, no. 1, pp. 60-68, 1973.

[12] A. Vandermeers, M. Vandermeers-Piet, J. Ratue and I. Christophe, "Competitive inhibitory effect excited by bile saly micelles on the hydrolysis of tributyrin by pancreatic lipase," Biochemical and Biophysical Research Communications, vol. 69, no. 3, pp. 790-797, 1976.

[13] H. Brockman, "Kinetic behavior of the pancreatic lipase-colipase-lipid system.," Biochimie., vol. 82, pp. 987-995, 2000. 
[14] D. D'Agostino, R. Cordle, J. Kullman, C. Erlanson-Albertsson, L. Muglia and M. Lowe, "Decreased postnatal survival and altered body weight regulation in procolipase deficient mice," Journal of Biological Chemistry, vol. 277, pp. 7170-7177, 2002.

[15] M. Charles, H. Sari, B. Entressangles and P. Desmuelle, "Interaction of pancreatic colipase with a bile salt micelle," Biochemical and Biophysical Resource Communications, vol. 65, no. 2, pp. 740$745,1975$.

[16] J. Hermoso , B. Pignol, S. Penel, M. Roth, C. Chapus and J. Fontecilla-Camps, "Neutron crystallographic evidence of lipase-colipase complex activation by a micelle," EMBO Journal, vol. 16, pp. 5531-5536, 1997.

[17] D. Pignol, L. Ayvazian, B. Kerfelec, P. Timmins, I. Crenon, J. Hermoso, J. Fontecilla-Camps and C. Chapus, "Critical role of micelles in pancreatic lipase activation revealed by small angle neutron scattering," Journal of Biological Chemistry, vol. 275, pp. 4220-4224, 2000.

[18] R. Verger, "Effects of co-lipase on hydrolysis of monomolecular films by lipase," Journal of Biological Chemistry, vol. 252, no. 12, pp. 4319-4325, 1977.

[19] M. Lowe, "Cloning and characterization of human pancreatic lipase cDNA," Journal of Biochemistry, vol. 264, pp. 20042-20048, 1989.

[20] F. Winkler, A. D'Arcy and W. Hunziker, "Structure of human pancreatic lipase," Nature, vol. 343, pp. 771-774, 1990.

[21] M. Egloff, L. Sarda, R. Verger, C. Cambillau and H. van Tilbeurgh, "Crystallographic study of the structure of colpiase and of the interaction with pancreatic lipase," Protein Science, vol. 4, pp. 44$57,1995$.

[22] H. Van Tilbeurgh, L. Sarda, R. Verger and C. Cambillau, "Structure of the pancreatic lipaseprocolipase complex," Nature, vol. 359, p. 1590162, 1992.

[23] H. Van Tilbeurgh, M. Egloff, C. Martinez, N. Rugani, R. Verger and C. Cambillau, "Interfacial activation of the lipase-procolipase complex by mixed micelles revealed by x-ray crystallography," Nature, vol. 362, pp. 814-820, 1993.

[24] M. Lowe, "Colipase stabilized the lid domain of pancreatic triglyceride lipase," Journal of Biological Chemistry, vol. 272, pp. 9-12, 1997.

[25] L. Brady, M. Brozozowski, Z. Derewenda, E. Dodson, G. Dodson, S. Tolley, J. Turkenburg, L. Christiansen, B. Huge-Jensen, L. Norskov, L. Thim and U. Menga, "A serine protease triad forms the catalytic centre of a triacylglycerol lipase," Nature, vol. 343, pp. 767-770, 1990.

[26] M. Lowe, "The catalytic site residues and interfacial binding of human pancreatic lipase.," Journal 
of Biological Chemistry, vol. 267, no. 24, pp. 17069-17073, 1992.

[27] J. Schrag, Y. Li, S. Wu and M. Cygler, "Ser-his-Glu triad forms the catalytic site of the lipase from Geotrichum candidum," Nature, vol. 351, pp. 761-764, 1991.

[28] J. Pleiss, M. Fischer and R. Schmid, "Anatomy of lipase binding sites: the scissile fatty acid binding site," Chemistry and Physics of Lipids, vol. 93, no. 1-2, pp. 67-80, 1998.

[29] H. Beer, G. Hohlfahrt, J. McCarthy, D. Schomburg and R. Schmid, "Analysis of the catalytic mechanism of a fungal lipase using computer-aided design and structural mutants," Protein Engineering, vol. 9, no. 6, pp. 507-517, 1996.

[30] M. Cygler, J. Schrag, J. Sussman, M. Harel, I. Silman, M. Gentry and B. Doctor, "Relationship between sequence conservation and three-dimensional structure in a large family of esterases, lipases, and related proteins.," Protein Science, vol. 2, no. 3, pp. 366-382, 1993.

[31] M. McArthur, B. Atshaves, A. Frolov, W. Forworth, A. Kier and F. Schroeder, "Cellular uptake and intracellular trafficking of long chain fatty acids," Journal of Lipid Research, vol. 40, pp. 1372$1383,1999$.

[32] J. Kampf, D. Cupp and A. Kleinfeld, "Different mechanisms of free fatty acid flip-flop and dissociation revealed by temperature and molecular species dependence of transport across lipid vesicles," Journal of Biological Chemistry, vol. 281, pp. 21566-21574, 2006.

[33] F. Wilson, V. Sallee and J. Dietschy, "Unstirred water layers in intestine: rate determinant of fatty acid absorption from micellar solutions," Science, vol. 174, pp. 1031-1033, 1971.

[34] Y. Shiau, P. Fernandez, M. Jackson and S. McMonagle, "Mechanisms maintaining a low-pH microclimate in the intestine," American Journal of Physiology, vol. 248, pp. 608-617, 1985.

[35] M. Orsenigo, M. Tosco, S. Zoppi and A. Faelli, "Characterization of basolateral membrane Na/H antiport in rat jejunum," Biochimica et Biophysica Acta, vol. 1026, pp. 64-68, 1990.

[36] P. Tso, "Intestinal lipid absorption," Physiology of the gastrointestinal tract, vol. 3rd, pp. 18671907, 1994.

[37] Y. Shiau, "Mechanisms of intestinal fat absorption," American Journal of Physiology, vol. 240, pp. $1-9,1981$.

[38] F. Kamp, H. Westterhoff and J. Hamilton, "Movement of fatty acids, fatty acid analogues and bile acids across phospholipid bilayers," Biochemistry, vol. 1236, pp. 51-64, 1993.

[39] F. Kamp, D. Zakim, F. Zhang, N. Noy and J. Hamilton, "Fatty acid flip-flop in phospholipid bilayers is extremely fast," Biochemistry, vol. 34, pp. 11928-11937, 1995. 
[40] A. Kleinfeld, P. Chu and C. Romero, "Transport of long-chain native fatty acids across lipid bilayer membranes indicates that transbilayer flip-flop is rate limiting," Biochemistry, vol. 36, pp. 1414614158, 1997.

[41] P. Berk and D. Stump, "Mechanisms of cellular uptake of long chain free fatty acids," Molecular and Cellular Biochemistry, vol. 192, no. 1-2, pp. 17-31, 1999.

[42] J. Hamilton, W. Guo and F. Kamp, "Mechanism of cellular uptake of long-chain fatty acids: do we need cellular proteins?," Molecular and Cellular Biochemistry, vol. 176, pp. 17-23, 2002.

[43] D. Zakim, "Thermodynamics of fatty acids transfer," Journal of Membrane Biology, vol. 176, pp. 101-109, 2000.

[44] G. Schulthess, G. Lipka, S. Compassi, D. Boffelli, F. Weber, F. Paltauf and H. Hauser, "Absorption of monoacylglycerols by small intestinal brush border membrane," Biochemistry, vol. 33, pp. 45004508, 1994.

[45] K. Murota and J. Storch, "Uptake of micellar long-chain fatty acid and sn-2-monoacylglycerol into human intestinal Caco-2 cells exhibits characteristics of protein-mediated transport," Journal of Nutrition, vol. 135, pp. 1626-1630, 2005.

[46] H. Shiu-Ying and J. Storch, "Common mechanisms of monoacylglycerol and fatty acid uptake by human intestinal Caco-2 cells," American Journal of Physiology and Cell Physiology, vol. 281, pp. 1106-1117, 2001.

[47] j. Brandner and R. Birkmeier, "The equilibrium distribution of acyl groups between primary and secondary hydroxyl positions in partial esters," Journal of the American oil Chemist Society, vol. 41, no. 5, pp. 367-370, 1964.

[48] H. Kayden, J. Senior and F. Mattson, "The monoglyceride pathway of fat absorption in man," The Journal of Clinical Investigation, vol. 46, no. 11, pp. 1695-1703, 1967.

[49] R. Cardell, S. Badenhausen and K. Porter, "Intestinal triglyceride absorption in the rat. An electron microscopic study," Journal of Cell Biology, vol. 34, p. 123, 1966.

[50] H. Friedman and R. Cardell, "Alterations in the endoplasmic reticulum and golgi complex of intestinal epithelial cells during fat absorption and after termination of this process: a morphological and morphometric study," The Anatomical Record, vol. 188, no. 1, pp. 77-101, 1977.

[51] E. Sjostrand and B. Borstrom, "The lipid components of the smooth-surfaced membrane-bound vesicles of the columnar cells of the rat intestinal epithelium during fat absorption," Journal of Ultrastructure Research, vol. 20, no. 1, pp. 140-160, 1967.

[52] H. Mollenhauer and W. Whaley, "An observation on the functioning of the Golgi apparatus," 
Journal of Cell Biology, vol. 17, pp. 222-225, 1963.

[53] J. Senior and K. Isselbacher, "Activation of long-chain fatty acids by rat-gut mucosa," Biochimica et Biophysica Acta, vol. 44, pp. 399-400, 1960.

[54] A. Stahl, D. Hirsch, R. Gimeno, S. Punreddy, P. Ge, N. Watson, S. Patel, M. Kotler, A. Raimondi, L. Tartaglia and H. Lodish, "Identification of the major intestinal fatty acid transport protein," Molecular Cell, vol. 4, pp. 299-308, 1999.

[55] K. Milger, T. Herrmann, C. Becker, D. Gotthardt, J. Zickwolf, R. Ehehalt, P. Watkins, W. Stremmel and J. Fullekrug, "Cellular uptake of fatty acids driven by the ER-localized acyl-CoA synthetase FATP4," Journal of Cell Science, vol. 119, pp. 4678-4688, 2006.

[56] N. Bass, " Function of regulation of hepatic and intestinal fatty acid binding proteins," Chemistry and Physics of Lipids, vol. 38, pp. 95-114, 1985.

[57] A. Thumser and J. Storch, "Liver and intestinal fatty acid-binding proteins obtain fatty acids from phospholipid membranes by different mechanisms," Journal of Lipid Research, vol. 41, pp. 647$656,2000$.

[58] A. Thumser and D. Wilton, "The binding of cholesterol and bile salts to recombinant rat liver fatty acid-binding protein," Biochemical Journal, vol. 320, pp. 729-733, 1996.

[59] J. Hamilton, "Fatty acid interactions with proteins: what X-ray crystal and NMR solution structures tell us," Progress in Lipid Research, vol. 43, pp. 177-199, 2004.

[60] D. Cistola, J. Sacchettini, L. banaszak, M. Walsh and J. Gordon, "Fatty acid interactions with rat intestinal and liver fatty acid-binding proteins expressed in Escherichia coli. A comparative 13C NMR study," Journal of Biological Chemistry, vol. 264, pp. 2700-2710, 1989.

[61] K. Hsu and J. Storch, "Fatty acid transfer from liver and intestinal fatty acid-binding proteins to membranes occurs by different mechanisms," Journal of Biological Chemistry, vol. 271, pp. 1331713323, 1996.

[62] D. Cheng, T. Nelson, J. Chen, S. Walker, J. Wardwell-Swanson, R. Meegalla, R. Taub, J. Billheimer, M. Ramaker and J. Feder, "Identification of acyl coenzyme A:monoacylglycerol acyltransferase 3, an intestinal specific enzyme implicated in dietary fat absorption," Journal of Biological Chemistry, vol. 278, pp. 13611-13615, 2003.

[63] C. Yen and R. Farese, "MGAT2, a monoacylglycerol acyltransferase expressed in the small intestine," Journal of Biological Chemistry, vol. 278, pp. 18532-18537, 2003.

[64] C. Yen, S. Stone, S. Koliwad, C. Harris and R. Farese, "Thematic review series: glycerolipids. DGAT enzymes and triacylglycerol biosynthesis," Journal of Lipid Research, vol. 49, pp. 2283- 
$2301,2008$.

[65] R. Bell, L. Ballas and R. Coleman, "Lipid topogenesis," Journal of Lipid Research, vol. 22, pp. 391-403, 1981.

[66] B. Lee, A. Fast, J. Zhu, J. Cheng and K. Buhman, "Intestine-specific expression of acyl CoA:diacylglycerol acyltransferase 1 reverses resistance to diet-induced hepatic steatosis and obesity in DGAT -/- mice," Journal of Lipid Research, vol. 51, pp. 1770-1780, 2010.

[67] S. Stone, M. Levin, P. Zhou, J. Han, T. Walther and R. Farese, "The endoplasmic reticulum enzyme DGAT2 is found in mitochondria-associated membranes and has a mitochondrial targeting signal that promotes its association with mitochondria," Journal of Biological Chemistry, vol. 284, pp. 5352-5361, 2009.

[68] T. Yamazaki, E. Sasaki, C. Kakinuma, T. Yano, S. Miura and O. Ezaki, "Increased very low density lipoprotein secretion and gonadal fat mass in mice overexpressing liver DGAT1," Journal of Biological Chemistry, vol. 280, no. 22, pp. 21506-21514, 2005.

[69] K. Buhman, S. Smith, S. Stone, J. Repa, J. Wong and F. Knapp, "DGAT1 is not essential for intestinal triacylglycerol absorption or chylomicron synthesis," Journal of Biological Chemistry, vol. 276, pp. 25474-25479, 2002.

[70] N. Broadway and E. Saggerson, "Solubilization and separation of two distinct carnitine acyltransferases from hepatic microsomes: characterization of the malonyl-CoA sensitive enzyme," Biochemical Journal, vol. 310, pp. 989-995, 1995.

[71] L. Washington and G. Cook, "Inhibition of carnitine palmitoyltransferase in the rat small intestine reduces export of triacylglycerol into the lymph," Journal of Lipid Research, vol. 44, pp. 13951403, 2003.

[72] L. Swift, A. Jovanovska, V. Kakkad and D. Ong, "Microsomal triglyceride transfer protein expression in mouse intestine," Histochemistry and Cell Biology, vol. 123, pp. 475-482, 2005.

[73] M. Smolenaars, O. Madesen, L. Rodenburg and D. Van der Horst, "Molecular diversity and evolution of the large lipid transfer protein superfamily," Journal of Lipid Research, vol. 48, pp. 489-502, 2007.

[74] A. Rusinol, H. Jamil and J. Vance, "In vitro reconstitution of assembly of apolipoprotein B48containing lipoproteins," Journal of Biological Chemistry, vol. 272, no. 12, pp. 8019-8025, 1997.

[75] X. Wu, M. Zhou, L. Huang, J. Wetterau and H. Ginsberg, "Demonstration of a physical interaction between microsomal triglyceride transfer protein and apolipoprotein B during the assembly of ApoB-containing lipoproteins," Journal of Biological Chemistry, vol. 271, pp. 10277-10281, 1996. 
[76] P. Rava and M. Hussain, "Acquisition of triacylglycerol transfer activity by microsomal triglyceride transfer protein during evolution," Biochemistry, vol. 46, pp. 12263-12274, 2007.

[77] H. Jamil, J. Dickson, C. Chu, M. Lago, J. Rinehart and S. Biller, "Microsomal triglyceride transfer protein. Specificity of lipid binding and transport," Journal of Biological Chemistry, vol. 270, pp. 6549-6554, 1995.

[78] Y. Xie, E. Newberry, S. Young, S. Robine, R. Hamilton, J. Wong, J. Luo, S. Kennedy and N. Davidson, "Compensatory incease in hepatic lipogenesis in mice with conditional intestine-specific Mttp deficiency," Journal of Biological Chemistry, vol. 281, pp. 4075-4086, 2006.

[79] M. Raabe, M. Veniant, M. Sullican, C. Zlot, J. Bjorkegran, L. Nielsen, J. Wong, R. Hamilton and S. Young, "Analysis of the role of microsomal triglyceride transfer protein in the liver of tissuespecific knockout mice," Journal of Clinical Investigation, vol. 103, pp. 1287-1298, 1999.

[80] R. Pariyarath, H. Wang, J. Aitchison, H. Ginsberg, W. Welch, A. Johnson and E. Fisher, "Cotranslational interactions of apoprotein B with the ribosome and translocon during lipoprotein assembly or targeting to the proteasome," Journal of Biological Chemistry, vol. 276, pp. 541-550, 2001.

[81] J. Liang, X. Wu, E. Fisher and H. Ginsberg, "The amino-terminal domain of apolipoprotein B does not undergo retrograde translocation from the endoplasmic reticulum to the cytosol. Proteosomal degradation of nascent apolipoprotein B begins at the carboxyl terminus of the protein, while apolipoprotein," Journal of Biological Chemistry, vol. 275, pp. 32003-32010, 2000.

[82] A. Kulinski, S. Rustaeus and J. Vance, "Microsomal triacylglycerol transfer protein is required for luminal accretion of triacylglycerol not associated with ApoB, as well as for ApoB lipidation," Journal of Biological Chemistry, vol. 277, pp. 21516-21525, 2002.

[83] C. Alexander, R. Hamilton and R. Havel, "Subcellular localization of B apoprotein of plasma lipoproteins in rat liver," Journal of Cell Biology, vol. 69, pp. 241-263, 1976.

[84] P. Tso, M. Liu, T. Kalogeris and A. Thomson, "The role of apolipoprotein A-IV in the regulation of food intake," Annual Review of Nutrition, vol. 21, pp. 231-254, 2001.

[85] C. Mansbach and P. Nevin, "Intracellular movement of triacylglycerols in the intestine," Journal of Lipid Research, vol. 39, no. 5, pp. 963-969, 1998.

[86] I. Neeli, S. Siddiqi, S. Siddiqi, W. Lagakos, B. Binas and T. Gheyi, "Liver fatty acid-binding protein initiates budding of pre-chylomicron transport vesicles from intestinal endoplasmic reticulum," Journal of Biological Chemistry, vol. 282, pp. 17974-17984, 2007.

[87] S. Siddiqi, U. Saleem, N. Abumrad, N. Davidson, J. Storch, S. Siddiqi and C. Mansbach, "A novel multiprotein complex is required to generate the prechylomicron transport vesicle from intestinal 
ER," Journal of Lipid Research, vol. 51, pp. 1918-1928, 2010.

[88] S. Siddiqi, S. Siddiqi, J. Mahan, K. Peggs, F. Gorelick and C. Mansbach, "The identification of a novel endoplasmic reticulum to Golgi SNARE complex used by the prechylomicron transport vesicle," Journal of Biological Chemistry, vol. 281, pp. 20974-20982, 2006.

[89] S. Siddiqi, S. Siddiqi and C. Mansbach, "Sec24C is required for docking the prechylomicron transport vesicle with the Golgi," Journal of Lipid Research, vol. 51, pp. 1093-1100, 2010.

[90] C. Shoulders, D. Stephens and B. Jones, "The intracellular transport of chylomicrons requires the small GTPase, Sar1b," Current Opinion in Lipidology, vol. 15, pp. 191-197, 2004.

[91] S. Siddiqi, F. Gorelick, J. Mahan and C. Mansbach, "COPII proteins are required for Golgi fusion but not for endoplasmic reticulum budding of the pre-chylomicron transport vesicle," Journal of Cell Science, vol. 116, pp. 415-427, 2003.

[92] N. Berriot-Varoqueaux, A. Dannoura, A. Moreau, N. Verthier and A. Sassolas, "Apolipoprotein B48 glycosylation in abetalipoproteinemia and Anderson's disease," Gastroenterology, vol. 121, pp. 1101-1108, 2001.

[93] S. Sabesin, S. Clark and P. Holt, "Ultrastructural features of regional differences in chylomicron secretion by rat intestine," Experimental and Molecular Pathology, vol. 26, pp. 277-289, 1977.

[94] J. Trier and J. Madara, "Functional morphology of mucosa of the small intestine," Physiology of the Gastrointestinal Tract, pp. 925-961, 1981.

[95] M. Papp, P. Rohlich, I. Rusznyaki and I. Toro, "An electron microscopic study of the central lacteal in the intestinal villus of the cat," Zeitschrift fur Zellforschung und Mikroskopische Anatomie, vol. 57, pp. 475-486, 1962.

[96] J. Casley-Smith, "Identification of chylomicra and lipoproteins in tissue sections and their passage into jejunal lacteals," Journal of Cell Biology, vol. 15, pp. 259-277, 1962.

[97] W. Dobbins and E. Rollins, "Intestinal mucosal lymphatic permeability—an electron microscopic study of endothelial vesicles and cell junctions," Journal of Ultrastructure Research, vol. 33, pp. 29-59, 1970.

[98] W. Dobbins, "Intestinal mucosal lacteal in transport of macromolecules and chylomicrons," American Journal of Clinical Nutrition, vol. 24, pp. 77-90, 1971.

[99] P. Tso, V. Pitts and D. Granger, "Role of lymph flow in intestinal chylomicron transport," American Journal of Physiology, vol. 249, pp. 21-28, 1985.

[100] S. Turner and J. Barrowman, "Intestinal lymph flow and lymphatic transport of protein during fat absorption," Quarterly journal of experimental physiology and cognate medical sciences, vol. 62, 
pp. 175-180, 1977.

[101] L. Leak and J. Burke, "Fine structure of the lymphatic capillary and the adjoining connective tissue area," American Journal of Anatomy, vol. 118, no. 3, pp. 785-809, 1966.

[102] N. Harvey, R. Srinivasan, M. Dillard, N. Johnson, M. Witte and K. Boyd, "Lymphatic vascular defects promoted by prox1 haploinsufficiency cause adult-onset obesity," Nature Genetics, vol. 37, pp. 1071-1081, 2005.

[103] M. Muthuchamy, A. Gashev, N. Boswell, N. Dawson and D. Zawieja, "Molecular and functional analyses of the contractile apparatus in lymphatic muscle," FASEB Journal, vol. 17, no. 8, pp. 920922, 2003.

[104] T. Kirchgessner, R. LeBoeuf, C. Langner, S. Zollman, C. Chang, B. Tayler, M. Schotz, J. Gordon and A. Lusis, "Genetic and developmental regulation of the lipoprotein lipase gene: loci both distal and proximal to the lipoprotein lipase structural gene control enzyme expression," Journal of Biological CHemistry, vol. 264, pp. 1473-1482, 1989.

[105] A. Beigneux, B. Davies, P. Gin, M. Weinstein, E. Farber, X. Qiao, F. Peale, S. Bunting, R. Walzem, J. Wong, W. Blaner, Z. Ding, K. Melford, N. Wongsirioj and X. Shu, "Glycosylphosphatidylinositol-anchored high-density lipoprotein-binding protein 1 plays a critical role in the lipolytic processing of chylomicrons," Cell Metabolism, vol. 5, no. 4, pp. 279-291, 2007.

[106] B. Davies, A. Beigneuz and R. Barnes, "GPIHBP1 is responsible for the entry of lipoprotein lipase into capillaries," Cell Metabolism, vol. 12, pp. 42-52, 2010.

[107] S. Eisenberg, E. Sehayek, T. Olivecrona and I. Vlodavsky, "Lipoprotein lipase enhances binding of lipoproteins to heparan sulfate on cell surfaces," Journal of Clinical Investigations, vol. 90, pp. 2013-2021, 1992.

[108] J. Augustin, F. Hudson, T. Pablito and V. Brown, "A comparison of molecular properties of hepatic triglyceride lipase and lipoprotein lipase from human post-heparin plasma," Journal of Biological Chemistry, vol. 253, no. 9, pp. 2912-2920, 1979.

[109] H. Wong, R. Davis, T. Thuren, J. Goers, J. Nikazy, M. Waite and M. Schotz, "Lipoprotein lipase domain function," Journal of Biological Chemistry, vol. 269, pp. 10319-10323, 1994.

[110] P. Kinnunen, R. Jackson, L. Smith, A. Gotto and J. Sparrow, "Activation of lipoprotein lipase by native and synthetic fragments of human plasma apolipoprotein C-II," Proceedings of the National Academy of Sciences of the United States of America, vol. 74, pp. 4848-4851, 1977.

[111] S. Fojo and H. Brewer, "Hypertriglyceridaemia due to genetic defects in lipoprotein lipase and apolipoprotein C-," Journal of Internal Medicine, vol. 231, pp. 669-677, 1992. 
[112] S. Tajima, S. Yokoyama and A. Yamamoto, "Mechanism of action of lipoprotein lipase on triolein particles: Effect of apolipoprotein C-II," Journal of Biochemistry, vol. 96, pp. 1753-1767, 1984.

[113] J. Braun and D. Severson, "Tissue-specific regulation of lipoprotein lipase," Canadian Medical Association Journal, vol. 147, no. 8, p. 1192, 1992.

[114] T. Olivecrona, G. Liu, M. Hultin and G. Bengtsson-Olivecrona, "Regulation of lipoprotein lipase," Biochemical Society Transactions, vol. 21, pp. 509-513, 1993.

[115] M. Bergo, G. Olivecrona and T. Olivecrona, "Diurnal rhythms and effects of fasting and refeeding on rat adipose tissue lipoprotein lipase," American Journal of Physiology-Endocrinology and Metabolism, vol. 271, pp. 1092-1097, 1996.

[116] I. Grosskopf, N. Baroukh, S. Lee, Y. Kamari, D. Harats, E. Rubin, L. Pennacchio and A. Cooper, "Apolipoprotein A-V deficiency results in marked hypertriglyceridemia attributable to decreased lipolysis of triglyceride-rich lipoproteins and removal of their remnants," Atherosclerosis, Thrombosis, and Vascular Biology, vol. 25, no. 12, pp. 2573-2579, 2005.

[117] J. Lee, P. Giannikopoulos, S. Duncan, J. Wang, C. Johansen, J. Brown, J. Plutzky, R. Hegele, L. Glimcher and A. Lee, "The transcription factor cyclic AMP-responsive element-binding protein $\mathrm{H}$ regulates triglyceride metabolism," Nature Medicine, vol. 17, no. 7, pp. 812-815, 2011.

[118] C. Semenkovich, M. Wims, L. Noe, J. Etienne and L. Chan, "Insulin regulation of lipoprotein lipase activity in 3T3-L1 adipocytes is mediated at posttranscriptional and posttranslational levels," Journal of Biological Chemistry, vol. 264, pp. 9030-9038, 1989.

[119] J. Ong and P. Kern, "The role of glucose and glycosylation in the regulation of lipoprotein lipase synthesis and secretion in rat adipocytes," Journal of Biological Chemistry, vol. 264, pp. 3177$3182,1989$.

[120] K. Schoonjans, J. Peinado-Onsurbe, A. lefebvre, R. Heyman, M. Briggs, S. Deeb, B. Staels and J. Auwerx, "PPARalpha and PPARgamma activators direct a distinct tissue-specific transcriptional response via a PPRE in the lipoprotein lipase gene," The EMBO Journal, vol. 15, no. 19, pp. 5336$5348,1996$.

[121] B. Staels, N. Vu-Dac, V. Kosykh, R. Saladin, J. Fruchart and J. Dallongeville, "Fibrates downregulate apolipoprotein C-III expression independent of induction of peroxisomal acyl coenzyme A oxidase. A potential mechanism for the hypolipidemic action of fibrates," Journal of Clinical Investigations, vol. 95, pp. 705-712, 1995.

[122] S. Khan, A. Minihane, P. Talmud, J. Wright, M. Murphy, C. Williams and B. Griffin, "Dietary long chain n-3 PUFAs increase LPL gene expression in adipose tissue of subjects with an atherogenic lipoprotein phenotype," Journal of Lipid Research, vol. 43, pp. 979-985, 2002. 
[123] N. Abumrad, C. Harmon and A. Ibrahimi, "Membrane transport of long-chain fatty acids. Evidence for a facilitated process," Journal of Lipid Research, vol. 39, pp. 2309-2318, 1998.

[124] D. Cupp, J. Kampf and A. Kleinfeld, "Fatty acid-albumin complexes and the determination of the transport of long chain free fatty acids across membranes," Biochemistry, vol. 43, no. 15, pp. 44734481, 2004.

[125] A. Baillie, C. Coburn and N. Abumrad, "Reversible binding of long-chain fatty acids to purified FAT, the adipose CD36 homolog," Journal of Membrane Biology, vol. 153, pp. 75-81, 1996.

[126] C. Coburn, F. Knapp, M. Febbraio, A. Beets, R. Silverstein and N. Abumrad, "Defective uptake and utilization of long chain fatty acids in muscle and adipose tissues of CD36 knockout mice," Journal of Biological Chemistry, vol. 275, pp. 32523-32529, 2000.

[127] R. Schwenk, J. Luiken, A. Bonen and J. Glatz, "Regulation of sarcolemmal glucose and fatty acid transporters in cardiac disease," Cardiovascular Research, vol. 79, pp. 249-258, 2008.

[128] Z. Nahle, M. Hsieh, T. Pietka, C. Coburn, P. Grimaldi, M. Zhang, D. Das and N. Abumrad, "CD36dependent regulation of muscle FoxO1 and PDK4 in the PPAR delta/beta-mediated adaptation to metabolic stress," Journal of Biological Chemistry, vol. 283, pp. 14317-14326, 2008.

[129] C. Bastie, Z. Nahle, T. McLoughlin, K. Esser, W. Zhang, T. Unterman and N. Abumrad, "FoxO1 stimulates fatty acid uptake and oxidation in muscle cells through CD36-dependent and independent mechanisms," Journal of Biological Chemistry, vol. 280, pp. 14222-14229, 2005.

[130] J. Schaffer and H. Lodish, "Expression cloning and characterization of a novel adipocyte long chain fatty acid transport protein," Cell, vol. 79, pp. 427-436, 1994.

[131] F. Schapp, B. Binas, H. Danneberg, G. Van Der Vusse and J. Glatz, "Glatz Impaired long-chain fatty acid utilization by cardiac myocytes isolated from mice lacking the heart-type fatty acid binding protein gene," Circulation Research, vol. 85, pp. 329-337, 1999.

[132] J. Glatz and J. Storch, "Unravelling the significance of cellular fatty acidbinding proteins," Current Opinion in Lipidology, vol. 12, pp. 267-274, 2001.

[133] G. Lopaschuk, "Malonyl CoA control of fatty acid oxidation in the diabetic rat heart," Advances in Experimental Medicine and Biology, vol. 498, pp. 155-165, 2001.

[134] R. Bell and R. Coleman, "Enzymes of triacylglycerol formation in mammals," The Enzymes, vol. 16, pp. 87-111, 1983.

[135] H. Stam, K. Schoonderwoerd and W. Hulsmann, "Synthesis, storage and degradation of myocardial triglycerides.," Basic Research in Cardiology, vol. 82, pp. 19-28, 1987.

[136] A. Pranprawit, F. Wolber, J. Heyes, A. Molan and M. Kruger, "Short-term and long-term effects of 
excessive consumption of saturated fats and/or sucrose on metabolic variables in Sprague Dawley rats: a pilot study," Journal of the Science of Food and Agriculture, 2013.

[137] K. Alberti, R. Eckel, S. Grundy, P. Zimmet, J. Cleeman and K. Donato, "Harmonizing the metabolic syndrome: a joint interim statement of the International Diabetes Federation Task Force on Epidemiology and Prevention; National Heart, Lung, and Blood Institute; American Heart Association; World Heart Federation; Internationa," Circulation, vol. 120, pp. 1640-1650, 2009.

[138] NHLBI, National Institutes of Health, National Heart, Lung, and Blood Institutes, 2009. [Online]. Available: nhlbi.nih.gov.

[139] A. Bernstein, E. Ding, W. Willett and E. Rimm, "A Meta-Analysis shows that docosahexaenoic acid from algal oil reduces serum triglycerides and increases hdl-cholesterol and ldl-cholesterol in persons without coronary heart disease," Journal of Nutrition, vol. 142, pp. 99-104, 2012.

[140] S. norell, A. Ahlbom, M. Feychting and N. Pedersen, "Fish consumption and mortality from coronary heart disease," British Medical Journal, vol. 293, p. 426, 1986.

[141] H. Bartsch, J. Nair and R. Owen, "Dietary polyunsaturated fatty acids and cancers of the breast and colorectum: emerging evidence for their role as risk modifiers," Carcinogenesis, vol. 20, pp. 2209$2218,1999$.

[142] Y. Adkins and D. Kelley, "Mechanisms underlying the cardioprotective effects of omega-3 polyunsaturated fatty acids," Journal of Nutritional Biochemistry, vol. 21, pp. 781-792, 2010.

[143] F. Roshanai and T. Sanders, "Assessment of fatty-acid intakes in vegans and omnivores," Human Nutrition - Applied Nutrition, vol. 38, pp. 345-354, 1984.

[144] M. Rosell, Z. Lloyd-Wright, P. Appleby, T. Sanders, N. Allen and T. Key, " Long-chain n-3 polyunsaturated fatty acids in plasma in British meat-eating, vegetarian, and vegan men," American Journal of Clinical Nutrition, vol. 82, pp. 327-334, 2005.

[145] H. Cho, M. Nakamura and S. Clarke, "Cloning, expression, and nutritional regulation of the mammalian Delta-6 desaturase," Journal of Biological Chemistry, vol. 274, pp. 471-477, 1999.

[146] J. Brenna, "Efficiency of conversion of alpha-linolenic acid to long chain n-3 fatty acids in man," Current Opinion in Clinical Nutritionand Metabolic Care, vol. 5, pp. 127-132, 2002.

[147] L. Arterburn, E. Hall and H. Oken, "Distribution, interconversion, and dose response of n-3 fatty acids in humans," American Journal of Clinical Nutrition, vol. 83, p. 1467, 2006.

[148] A. Ayalew-Pervanchon, D. Rousseau, D. Moreau, P. Assayag, P. Weill and A. Grynberg, "Longterm effect of dietary $\alpha$-linolenic acid or decosahexaenoic acid on incorporation of decosahexaenoic acid in membranes and its influence on rat heart in vivo," American Journal of Physiology - Heart 
and Circulatory Physiology, vol. 293, pp. 2296-2304, 2007.

[149] S. Mandasescu, V. Mocanu, A. Dascalita, R. Haliga, I. Nestian, P. Stitt and V. Luca, "Flaxseed supplementation in hyperlipidemic patients," Revista medico-chirurgicala a Societatii de Medici si Naturalisti din Iasi, vol. 109, no. 3, pp. 502-506, 2005.

[150] S. Cunnane, S. Ganguli, C. Menard, A. Liede, M. Hamadeh and Z. Chen, "High alpha-linolenic acid flaxseed (Linum usitatissimum): some nutritional properties in humans," British Journal of Nutrition, vol. 69, pp. 443-453, 1993.

[151] S. Cunnane, M. Hamadeh, A. Liede, L. Thompson, T. Wolever and D. Jenkins, "Nutritional attributes of traditional flaxseed in healthy young adults," American Journal of Clinical Nutrition, vol. 61, pp. 62-68, 1995.

[152] D. Nieman, E. Cayea, M. Austin, D. Henson, S. McAnulty and F. Jin, "Chia seed does not promote weight loss or alter disease risk factors in overweight adults," Nutritional Research, vol. 29, pp. 414-418, 2009.

[153] L. Arterburn, H. Oken, J. Hoffman, E. Bailer-Hall, G. Chung, D. Rom, J. Hamersley and D. McCarthy, "Bioequivalence of Docosahexaenoic acid from different algal oils in capsules and in a dha-fortified food," Lipids, vol. 42, pp. 1011-1024, 2007.

[154] D. Kelley, D. Siegel, M. Vemuri and B. Mackey, "Docosahexaenoic acid supplementation improves fasting and postprandial lipid profiles in hypertriglyceridemic men," American Journal of Clinical Nutrition, vol. 86, pp. 324-333, 2007.

[155] K. Stark and B. Holub, "Differential eicosapentaenoic acid elevations and altered cardiovascular disease risk factor responses after supplementation with docosahexaenoic acid in postmenopausal women receiving and not receiving hormone replacement therapy," American Journal of Clinical Nutrition, vol. 79, no. 5, pp. 765-773, 2004.

[156] H. Theobald, P. Chowienczyk, R. Whittall, S. Humphries and T. Sanders, "LDL cholesterol-raising effect of low-dose docosahexaenoic acid in middle-aged men and women," American Journal of Clinical Nutrition, vol. 79, pp. 558-563, 2004.

[157] L. Belcher, S. MacKenzie, M. Donner, G. Sykes, S. Frame and P. Gillies, "Safety assessment of EPA-rich triglyceride oil produced from yeast: Genotoxicity and 28-day oral toxicity in rats," Regulatory Toxicology and Pharmacology, vol. 59, pp. 53-63, 2010.

[158] S. MacKenzie, L. Belcher, G. Sykes, S. Frame, P. Mukerji and P. Gillies, "Safety assessment of EPA-rich oil produced from yeast: Results of a 90-day subchronic toxicity study," Regulatory Toxicology and Pharmacology, vol. 58, pp. 490-500, 2010.

[159] G. Chinetti, S. Lestavel, V. Bocher, A. Remaley, B. Neve, I. Torra, E. Teissier, A. Minnich, M. Jaye, N. Duverger, H. Brewer, Frucart, V. Clavery and B. Staels, "PPAR-alpha and PPAR-gamma 
activators induce cholesterol removal from human macrophage foam cells through stimulation of the ABCA1 pathway," Nature Medicine, vol. 7, pp. 53-58, 2001.

[160] Y. Lu, E. Feskens, M. Dolle, S. Imholz, M. Verschuren, M. Muller and J. Boer, "Dietary n-3 and n6 polyunsaturated fatty acid intake interacts with FADS1 genetic variation to affect total and HDLcholesterol concentrations in the Doetinche, Cohort Study," American Journal of Clinical Nutrition, vol. 92, no. 1, pp. 258-265, 2010.

[161] M. Yokoyama, H. Origasa, M. Matsuzaki, Y. Matsuzawa, Y. Saito, Y. Ishikawa, S. Oikawa, J. Sasaki, H. Hishida, H. Itakura, Y. Kita, A. Kitabatake, N. Nakaya, T. Sakata, K. Shimada and K. Shirato, "Effects of eicosapentaenoic acid on major coronary events in hypercholesterolaemic patients (JELIS): a randomised open-label, blinded endpoint analysis," The Lancet, vol. 369, pp. 1090-1098, 2007.

[162] J. Wilkinson, J. Higgins, C. Fitzsimmons and D. Bowyer, "Dietary fish oils modify the assembly of VLDL and expression of the LDL receptor in rabbit liver," Atheriosclerosis, Thrombosis, and Vascular Biology, vol. 18, pp. 1490-1497, 1998.

[163] P. Valdivielso, J. Rioja, C. Garcia-Arias, M. Sanchez-Chaparro and P. Gonzalez-Santos, "Omega 3 fatty acids induce a marked reduction of apolipoprotein B48 when added to fluvastatin in patients with type 2 diabetes and mixed hyperlipidemia: a preliminary report," Cardiovascular Diabetology, vol. 8, p. 1, 2009.

[164] A. Skulas-Ray, P. Kris-Etherton, W. Harris, J. Vanden Heuvel, P. Wagner and S. West, "Doseresponse effects of omega-3 fatty acids on triglycerides, inflammation, and endothelial function in healthy persons with moderate hypertriglyceridemia," American Journal of Clinical Nutrition, vol. 93, pp. 243-252, 2011.

[165] L. Belalcazar, D. Reboussin, S. Haffner, R. Reeves, D. Schwenke and R. Hoogeveen, "Marine omega-3 fatty acid intake: associations with cardiometabolic risk and response to weight loss intervention in the Look AHEAD (Action for Health in Diabetes) study," Diabetes Care, vol. 33, pp. 197-199, 2009.

[166] G. Shelness and J. Sellers, "Very-low-density lipoprotein assembly and secretion," Current Opinion in Lipidology, vol. 12, pp. 151-157, 2001.

[167] M. Brown and J. Goldstein, "The SREBP pathway: regulation of cholesterol metabolism by proteolysis of a membrane-bound transcription factor," Cell, vol. 89, pp. 331-340, 1997.

[168] A. Pawar, D. Botolin, D. Mangelsdorf and D. Jump, "The role of liver X receptor- $\alpha$ in the fatty acid regulation of hepatic gene expression," Jounal of Biological Chemistry, vol. 278, pp. 40736-40743, 2003.

[169] J. Repa and D. Mangelsdorf, "The role of orphan nuclear receptors in the regulation of cholesterol 
homeostasis," Annual Review of Cell and Developmental Biology, vol. 16, pp. 459-481, 2000.

[170] H. Kim, M. Takahashi and O. Ezaki, "Fish oil feeding decreases mature sterol regulatory elementbinding protein 1 (SREBP-1) by down-regulation of SREBP-1c mRNA in mouse liver," Journal of Biological Chemistry, vol. 274, pp. 25892-25898, 1999.

[171] G. Howell, X. Deng, C. Yellaturu, E. Park, H. Wilcox, R. Raghow and M. Elam, "N-3 polyunsaturated fatty acids suppress insulin-induced SREBP-1c transcription via reduced transactivating capacity of LXRalpha," Biochimica et Biophysica Acta, vol. 1791, no. 12, pp. 11901196, 2009.

[172] D. Botolin, Y. Wang, B. Christian and D. Jump, "Docosahexaneoic acid (22:6, n-3) regulates rat hepatocyte SREBP-1 nuclear abundance by Erk- and 26S proteasome-dependent pathways," Journal of Lipid Research, vol. 47, pp. 181-192, 2006.

[173] H. Sampath and J. Ntambi, "Polyunsaturated fatty acid regulation of gene expression," Nutrition Reviews, vol. 62, no. 9, pp. 333-339, 2004.

[174] J. Ou, H. Tu, B. Shan, A. Luk, R. DeBose-Boyd, Y. Bashmakov, J. Goldstein and M. Brown, "Unsaturated fatty acids inhibit transcription of the sterol regulatory element-binding protein-1c (SREBP-1c) gene by antagonizing ligand-dependent activation of the LXR," Proceedings of the National Academy of Sciences of the United States of America, vol. 98, pp. 6027-6032, 2001.

[175] I. Pineda Torra, P. Gervois and B. Staels, "Peroxisome proliferator-activated receptor in metabolic disease, inflammation, atherosclerosis and aging," Current Opinion in Lipidology, vol. 10, pp. 151$159,1999$.

[176] S. Mandard, M. Muller and S. Kersten, "Peroxisome proliferator-activated receptor alpha target genes," Cellular and Molecular Life Sciences, vol. 61, no. 4, pp. 393-416, 2004.

[177] K. Miyata, S. McCaw, H. Patel, R. Rachubinski and J. Capone, "The orphan nuclear hormone receptor LXR alpha interacts with the peroxisome proliferator-activated receptor and inhibits peroxisome proliferator signaling," Journal of Biological Chemistry, vol. 271, pp. 9189-9192, 1996.

[178] M. Davidson, "Mechanisms for the hypotriglyceridemic effect of marine omega-3 fatty acids," American Journal of Cardiology, vol. 98, pp. 27-33, 2006.

[179] I. Hainault, M. Carolotti, E. Hajduch, C. Guichard and M. Lavau, "Fish oil in a high lard diet prevents obesity, hyperlipemia, and adipocyte insulin resistance in rats," Annals of the New York Academy of Science, vol. 683, pp. 98-101, 1993.

[180] C. Parrish, D. Pathy, J. Parkes and A. Angel, "Dietary fish oils limit adipose tissue hypertrophy in rats," Metabolism, vol. 39, pp. 217-219, 1990. 
[181] J. Ruzickova, M. Rossmeisl, T. Prazak, P. Flachs, J. Sponarova, M. Veck, T. Tvrzicka, M. Bryhn and J. Kopecky, "Omega-3 PUFA of marine origin limit diet-induced obesity in mice by reducing cellularity of adipose tissue," Lipids, vol. 39, pp. 1177-1185, 2004.

[182] X. Huang, X. Xin, P. McLennan and L. Storlien, "Role of fat amount and type in ameliorating dietinduced obesity: Insights at the level of hypothalamic arcuate nucleus leptin receptor neuropeptide Y and pro-opiomelanocortin mRNA expression," Diabetes, Obesity, and Metabolism, vol. 6, pp. 35-44, 2004.

[183] F. Belzung, T. Raclot and R. Groscolas, "Fish oil n-3 fatty acids selectively limit the hypertrophy of abdominal fat depots in growing rats fed high-fat diets," American Journal of Physiology, vol. 264, pp. 1111-1118, 1993.

[184] G. Power and E. Newsholme, "Dietary fatty acids influence the activity and metabolic control of mitochondrial carnitine palmitoyltransferase I in rat heart and skeletal muscle," Journal of Nutrition, vol. 127, pp. 2142-2150, 1997.

[185] S. Laurente-Cebrian, M. Bustos, A. Marti, J. Martinez and M. Moreno-Aliaga, "Eicosapentaenoic acid stimulates AMP-activated protein kinase and increases visfatin secretion in cultured murine adipocytes," Clinical Science, vol. 117, pp. 243-249, 2009.

[186] T. Motawi, R. Hashem, L. Rashed and S. El-Razek, "Comparative study between the effect of the peroxisome proliferator activated receptor-alpha ligands fenofibrate and n-3 polyunsaturated fatty acids on activation of 5'-AMP-activated protein kinase-alpha1 in high-fat fed rats," Journal of Pharmacy and Pharmacology, vol. 61, pp. 1339-1346, 2009.

[187] R. Baillie, R. Takada, M. Nakamura and S. Clarke, "Coordinate induction of peroxisomal acyl-CoA oxidase and UCP-3 by dietary fishoil: A mechanism for decreased body fat deposition," Prostaglandins, Leukotrienes, and Essential Fatty Acids. , vol. 60, pp. 351-356, 1999.

[188] J. Reddy and G. Mannaerts, " Peroxisomal lipid metabolism," Annual Review of Nutrition, vol. 14, pp. 343-370, 1994.

[189] P. Flachs, O. Horakova, P. Brauner, M. Rosseisl, P. Pecina, N. Franssen-van Hal, J. Ruzickova, J. Sponarova, Z. Drahota, C. Vlcek, J. Keijer, J. Houstek and J. Kopecky, "Polyunsaturated fatty acids of marine origin upregulate mitochondrial biogenesis and induce $\beta$-oxidation in white fat," Diabetologia, vol. 48, pp. 2365-2375, 2005.

[190] D. Kelly and R. Scarpulla, "Transcriptional regulatory circuits controlling mitochondrial biogenesis and function," Genes and Development, vol. 18, pp. 357-368, 2004.

[191] H. Poudyal, S. Panchal, L. Ward and L. Brown, "Effects of ALA, EPA and DHA in highcarbohydrate, high-fat diet-induced metabolic syndrome in rats," Journal of Nutritional Biochemistry, vol. 25, no. 6, pp. 1041-1052, 2012. 
[192] E. Wendland, A. Farmer, P. Glasziou and A. Neil, "Effect of alpha-linolenic acid on cardiovascular risk markers: a systematic review," Heart, vol. 92, pp. 166-169, 2006.

[193] Y. Park and W. Harris, "Omega-3 fatty acid supplementation accelerates chylomicron triglyceride clearance," Journal of Lipid Research, vol. 44, no. 3, pp. 455-463, 2003.

[194] S. Egert, F. Kannenberg, V. Somoza, H. Erbersdobler and U. Wharburg, "Dietary $\alpha$-Linolenic Acid, EPA, and DHA have differential effects on LDL fatty acid composition but similar effects on serum lipid profiles in normolipidemic humans," Journal of Nutrition, vol. 139, no. 5, pp. 861-868, 2009.

[195] D. Mozaffarian and J. Wu, "(n-3) fatty acids and cardiovascular health: Are effects of EPA and DHA shared or complementary?," Journal of Nutrition, vol. 142, pp. 614-625, 2012.

[196] A. Pawar and D. Jump, "Unsaturated fatty acid regulation of peroxisome proliferator-activated receptor alpha activity in rat primary hepatocytes," Journal of Biological Chemistry, vol. 278, pp. 35931-35939, 2003.

[197] B. Forman, J. Chen and R. Evans, "Hypolipidemic drugs, polyunsaturated fatty acids, and eicosanoids are ligands for peroxisome proliferator-activated receptors alpha and delta," Proceedings of the National Academy of Science, vol. 94, pp. 4312-4317, 1997.

[198] R. Pietrofesa, M. Azain and K. Barnes, "Lipidemic and cholesterolemic effects of feeding an algal source of docosahexaenoic acid to miceproliferator-activated receptors alpha and delta," the FASEB Journal, vol. 24, p. Abstract\#939.8, 2010.

[199] A. Shelton, R. Pietrofesa and K. Barnes, "Effect of high docosahexaenoic acid-algal oil on body fat and serum lipids in mice," The FASEB Journal, vol. 25, p. Abstart\# 586.5, 2011.

[200] P. Park and R. Goins, "In Situ preparation of fatty acid methyl esters for analysis of fatty acid composition in foods," Journal of Food Science, vol. 59, no. 6, pp. 1262-1266, 2006.

[201] E. Bligh and W. Dyer, "A rapid method of total lipid extraction and purification," Canadian Journal of Biochemistry and Physiology, vol. 37, no. 8, pp. 911-917, 1959.

[202] K. Fritshe and P. Johnston, "Effect of dietary-linolenic acid on growth, metastasis, fatty acid profile and prostaglandin production of two murine mammory adenocarcinomas," Journal of Nutrition, vol. 120, pp. 1601-1609, 1990.

[203] S. Smith, A. Yang, T. Larsen and R. Tume, "Positional analysis of triacylglycerols from bovine adipose tissue lipids varying in degree of unsaturation," Lipids, vol. 33, no. 2, pp. 197-207, 1998.

[204] A. Sala-Villa, A. Castellote and C. Lopez-Sabater, "The intramolecular position of docosahexaenoic acid in the triacylglycerol sources used for pediatric nutrition has a minimal effect on its metabolic use," Nutrition Research, vol. 28, pp. 131-136, 2007. 
[205] M. Rodavich, "The Effect of Non-Marine vs. Marine Sources of the Omega-3 Fatty Acids, DHA and EPA, on Serum Lipoproteins," West Virginia University, 2013.

[206] N. Abumrad and N. Davidson, "Role of the gut in lipid homeostasis," Physiological Reviews, vol. 92, no. 3, pp. 1061-1085, 2012.

[207] J. Wang and F. Sahidi, "Effect of enzymatic randomization on positional distribution and stability of seal blubber and menhaden oils," Journal of Agricultural and Food Chemistry, vol. 59, pp. 42324237, 2011.

[208] L. Yang, A. Kuksis and J. Myher, "Lipolysis of menhaden oil triacylglycerols and the corresponding fatty acid alkyl esters by pancreatic lipase in vitro: a reexamination.," Journal of Lipid Research, vol. 31, no. 1, pp. 137-147, 1990.

[209] A. Valenzuela, S. nieto, J. Sanhuez, M. Nunez and C. Ferrer, "Tissue accretion and milk content of docosahexaenoic acid in female rats after supplementation with different docosahexaenoic acid sources," Annals of Nutrition and Metabolism, vol. 49, no. 5, pp. 325-332, 2005.

[210] W. Harris, G. Lu, G. Rambjor, A. Walen, J. Ontko, Q. Cheng and S. Windsor, "Influence of n-3 fatty acid supplementation on the endogenous activities of plasma lipases.," American Journal of Clinical Nutrition, vol. 66, no. 2, pp. 254-260, 1997.

[211] H. Takayama, M. Gimbrone and A. Schafer, "Preferential incorporation of eicosanoid precursor fatty acids into human umnilical vein endothelial cell phospholipids," Biochimica et Biophysica Acta, vol. 922, no. 3, pp. 314-322, 1987.

[212] M. Christensen, B. Mortimer, C. Hoy and T. Redgrave, "Clearance of chylomicrons following fish oil and seal oil feeding," Nutrition Research, vol. 15, no. 3, pp. 359-368, 1995.

[213] "Proteopedia," [Online]. Available: http://proteopedia.org/wiki/index.php/Lipase. [Accessed 7 July 2013].

[214] P. Berk and D. Stump, ". Mechanisms of cellular uptake of long chain free fatty acids," Molecular and Cellular Biochemistry, vol. 192, no. 1-2, pp. 17-31, 1999.

[215] J. Casley-Smtih, ". Identification of chylomicra and lipoproteins in tissue sections and their passage into jejunal lacteals," Journal of Cell Biology, vol. 15, pp. 259-277, 1962.

[216] W. Dobbins and E. Rollins, ". Intestinal mucosal lymphatic permeability — an electron microscopic study of endothelial vesicles and cell junctions," Journal of Ultrastructure Research, vol. 33, pp. 29-59, 1970. 